\title{
Identification of Semiparametric Model Coefficients, With an Application to Collective Households
}

\author{
Arthur Lewbel* and Xirong Lin \\ Boston College and Shanghai University of Finance and Economics
}

Original November 2019, Revised January 2021

\begin{abstract}
We prove identification of coefficients for a set of semiparametric specifications that are related to multiple index models. Potential applications of these results include models of observed heterogeneity in production functions and in consumer demand systems. We then generalize these results to identify a class of collective household consumption models. We extend the existing literature by proving point identification, rather than the weaker generic identification, of all the features of the collective household model, including price effects. We estimate the model using Japanese consumption data, and find substantial variation in resource shares and indifference scales across households of different sizes.
\end{abstract}

\section{Introduction}

Let $p=\left(p_{1}, \ldots, p_{J}\right)$ be a vector of observed covariates (these will be prices in our empirical application), and let $s$ be an observed discretely distributed vector or index. Consider models of the

*JEL codes: C21, C31, D12, D13. Keywords: Identification, Semiparametric, Collective Household Model, Cost of Children, Bargaining Power, Sharing Rule, Demand Systems. Corresponding Author: Arthur Lewbel, Department of Economics - Maloney 315, Boston College, 140 Commonwealth Ave., Chestnut Hill, MA, 02467, USA. (617)-552-3678, lewbel@bc.edu, https://sites.google.com/bc.edu/arthurlewbel/ 
form $M(p, s)=G\left(a_{s 1} p_{1}, \ldots, a_{s J} p_{J}\right)$ where the function $M$ is known or identified, e.g., $M$ could be a conditional mean function estimated by nonparametric regression. We wish to point identify, up to normalization, the vector of coefficients $a_{s}=\left(a_{s 1}, \ldots, a_{s J}\right)$ for each value that $s$ can take on.

Note that this is not a single linear index model. Many results exist for identifying coefficients in linear index models, i.e., models that are functions of $a_{1} p_{1}+\ldots+a_{j} p_{j}$. But those results are not applicable to this context. Here each $p_{j}$ appears separately, and generally nonlinearly, in the function $G$. Still, as we show below, multiple (rather than single) linear index models do form a special case of the models we consider, so our results add to the existing literature on identification of multiple linear index models.

We provide three different assumptions that suffice to point identify the coefficients $a_{s j}$ for $j=1, \ldots, J$. Each assumption has different strengths and weaknesses, so different ones will be more or less useful depending on context. An attractive feature of these identification results is that they do not impose any monotonicity on the function $G$.

We then extend these results to show point identification of a general set of collective household consumption models. There is a long literature on the identification and estimation of collective household models of consumption. These are models of households with multiple members, each of whom maximizes a utility function, subject to their claims on the household's resources and a household budget constraint. Objects of particular interest are resource shares, defined as the fractions of household resources spent on each family member. Virtually all of the identification results in this collective household model literature either point identify specific functional forms, or point identify only a subset of the model's features, or only establishes either set or generic identification rather than point identification.

Generic identification of a model means that the model is usually point identified, but there can exist situations where point identification fails. More formally, generic identification says that in the set of all possible data generating processes that satisfy the model's assumptions, the subset for which point identification fails has measure zero. See McManus (1992) and Lewbel (2019) for more details regarding the formal definition of generic identification.

The well known collective household identification results of Chiappori and Ekeland (2006, 2009) and earlier authors, showing nonparametric identification up to unknown levels for resource shares, are generic identification theorems. As a result, there exist functional forms where point identification fails. For example, their model is not nonparametrically point identified if household members have Cobb-Douglas preferences. Moreover, as is typical for generic identification results, 
these authors do not fully characterize when point identification fails and when it does not. ${ }^{1}$ What we do is essentially add some additional assumptions and information that suffices to rule out all cases that are not point identified, and we do so for a set of models that is more general than theirs in terms of joint and shared consumption of goods.

After providing a few different sets of sufficient conditions for establishing point identification of the relative indices $a_{s j}$ above, we extend these theorems to point identify the related but more complicated structure of collective household models. We then illustrate the results by estimating a collective household model with Japanese data, where we find some new results regarding the sharing and division of goods among husbands, wives, and children. In particular, we find wide variation in resource shares by household size, though relatively little variation in total household economies of scale to consumption.

\section{Examples}

Let $A_{s}$ be a diagonal matrix with the vector $a_{s}=\left(a_{s 1}, \ldots, a_{s J}\right)$ on the diagonal. We first consider models of the form

$$
M(p, s)=G\left(a_{s 1} p_{1}, \ldots, a_{s J} p_{J}\right)=G\left(A_{s} p\right)
$$

Our goal is identification of the $a_{s}$ vectors and the function $G$. Examples of such models in the economics literature include the following.

1. Consumption taste heterogeneity. Consider a continuous consumption demand function $w=M(p, s)+e$ where $w$ is a single consumer's (not a household's) budget share for some good, $p$ is prices divided by total expenditures, and $s$ are observed demographic characteristics. Modeling taste heterogeneity in the form of equation (1), with the coefficients $a_{s j}$ being commodity specific equivalence scales (most commonly, so-called Barten scales), has a long history in demand system estimation. See, e.g., Prais and Houthakker (1955), Barten (1964), Pollak and Wales (1981), Jorgenson, Lau, and Stoker (1982), Folkertsma, (1995), Lewbel and Pendakur (2017), and Ray (2018).

2. Production function heterogeneity. Consider a production function $q=M(p, s)+e$ where $q$ is output, $p$ is a vector of input quantities, and $s$ is a set of firm characteristics. Then

\footnotetext{
${ }^{1}$ Browning, Chiappori, and Lewbel (2013) provide more details on this point. They also only show generic identification.
} 
equation (1) holds where each $a_{s j}$ captures the non-neutral technical efficiency of input $j$, and/or the quality of input $j$, by a firm with characteristics $s$. More generally, the $p$ in $M(p, s)$ could be a vector of both input and output prices in a multiple output production process, with signs of $a_{s j}$ determining which elements are inputs and which are outputs in a firm with characteristics $s$. A large literature exists on modeling heterogeneity in non-neutral efficiency in both macro, as in Basu and Fernald (1997), and industrial organization, as in Ackerberg, Caves, and Frazer (2015), and Gandhi, Navarro, and Rivers (2020).

3. Multiple linear index models. These can be constructed as a special case of our model. Suppose we add the constraint that all $a_{s j}$ and $p_{j}$ are strictly positive (this constraint will apply in our empirical application). Then we can equivalently write equation (1) as $M(p, s)=$ $\widetilde{G}\left(\ln a_{s 1}+\ln p_{1}, \ldots, \ln a_{s J}+\ln p_{J}\right)$. Since $s$ has finite support we can next equivalently replace each $\ln a_{s j}$ with a saturated model $\ln a_{j}(s)=\alpha_{j}^{\prime} S$ where $S$ is a vector of binary variables indicating each possible value in the support of $s$. We then get $M(p, s)=\widetilde{G}\left(\alpha_{1}^{\prime} S+\ln p_{1}, \ldots, \alpha_{j}^{\prime} S+\ln p_{J}\right)$, which is a multiple linear index structure. Multiple linear index models are popular structures in statistics and econometrics, with estimators including Ichimura and Lee (1991), Horowitz (1998), Xia, Tong, Li, and Zhu (2002), Xia (2008), Donkers and Schafgans (2008), and Ahn, Ichimura, Powell, and Ruud (2018). The restriction that each linear index has one explanatory variable that appears only in that index, with a coefficient of one (corresponding to the $\ln p_{j}$ terms in $\widetilde{G}$ ) appears as Assumption 3a in Donkers and Schafgans (2008). They observe this is one way to satisfy some necessary conditions for identification that appeared previously in the literature. Note that, in addition to the constraint that all $a_{s j}$ and $p_{j}$ in our model be strictly positive, the multiple linear index literature mostly focuses on applications where regressors are continuous, rather than our opposite extreme where only $p$ is continuous.

4. Collective Household Models. The modern literature on Pareto efficient collective household models begins with Becker $(1965,1981)$ and Chiappori (1988, 1992). An important series of papers in this literature establishes that, from only observing the demand functions of households, one cannot point identify resource shares (a resource share is the fraction of a household's total resources that are spent on the utility of any one household member). However, one can generically identify the marginal effects of policy variables on resource shares. Equivalently, each resource share is only point identified up to an unknown location constant. See, e.g., Browning, Bourguignon, Chiappori, and Lechene (1994), Browning and Chiappori (1998), Vermeulen (2002), and Chiappori 
and Ekeland $(2006,2009){ }^{2}$ Prominent papers that make use of these identification results include Chiappori, Fortin, and Lacroix (2002), and Blundell, Chiappori, and Meghir (2005).

By adding additional assumptions, more recent papers either generically identify the entire model, including the levels of resource shares, e.g., Browning, Chiappori, and Lewbel (2013), or point identify some features of the model (such as resource shares without price effects), e.g., Lewbel and Pendakur (2008), Bargain and Donni (2012), Dunbar, Lewbel, and Pendakur (2013), and Penglase (2019). Still other papers impose additional parametric restrictions to obtain point identification, e.g., Couprie, Peluso, and Trannoy (2010) and Lise and Seitz (2011).

None of the above results accomplish our goal, which is to provide sufficient conditions to semiparametrically point identify (not just generically identify) an entire collective household model, including resource share levels and price effects.

One large, general class of collective household models in the literature is based on Browning, Chiappori, and Lewbel (2013), which we will hereafter refer to as BCL. All but a handful of the papers cited above can be cast as special cases of BCL. BCL yields demands that can be written as a system of equations, each having a form resembling ${ }^{3}$

$$
M(p, s, y)=G\left(A_{s} p, \eta_{s}\left(A_{s} p\right) y\right)
$$

where $M$ is quantity demand, $G$ and $\eta_{s}$ are unknown functions, $p$ is a vector of observed prices, $y$ is observed total expenditures, $\eta_{s}$ is a resource share function, and the $a_{s j}$ terms on the diagonal of $A_{s}$ are parameters that summarize how much each good $k$ is shared among the household members (BCL calls this a Barten consumption technology, and calls these $a_{s j}$ terms Barten coefficients, due to their resemblance to Barten scales).We extend our results on point identification of equation (1) by providing sufficient conditions to point identify the BCL model.

\footnotetext{
${ }^{2}$ Although not point identified without additional information, bounds can be obtained on resource shares via revealed preference theory. See Cherchye, De Rock, and Vermeulen (2012a, 20102b), Cherchye, De Rock, Lewbel, and Vermeulen (2015), and Cherchye, Demuynck, De Rock, and Vermeulen (2017).

${ }^{3}$ Equation (2) is a special case of the more general demand functions obtained by BCL. The special case of equation (2) is for a single good in a two person household. We will later identify a more general model, consisting of multiple equations of this form with multiple resource shares, which also includes some cross equation restrictions that are helpful for the identification.
} 


\section{Semiparametric Coefficient Identification}

Let $a_{s}=\left(a_{s 1}, \ldots, a_{s J}\right)$ be a $J$-vector of coefficients we wish to identify. Let $A_{s}$ be the $J$ by $J$ diagonal matrix that has the vector $a_{s}$ on the diagonal. Let $P=\left(P_{1}, \ldots, P_{J}\right)$ be a $J$-vector of continuous covariates (possibly also including some mass points) and let $S$ be a discrete covariate (or vector of covariates). Assume we can identify a function $M(P, S)$, e.g., $M(P, S)$ might be a conditional mean, conditional density, or conditional quantile function that we could consistently estimate. The goal is to identify the unknown vector of coefficients $a_{s}=\left(a_{s 1}, \ldots, a_{s J}\right)$ in the model

$$
M(p, s)=G\left(a_{s 1} p_{1}, \ldots, a_{s J} p_{J}\right)=G\left(A_{s} p\right)
$$

for some unknown function $G$.

In this section we provide three alternative sets of conditions, each of which suffice for point identification of the vector of coefficients $\left(a_{s 1}, \ldots, a_{s J}\right)$ for each value $s$ that $S$ can equal. Each has relative advantages and disadvantages. None, however, require monotonicity of the function $G$. The following two assumptions are common to all three sets of assumptions.

ASSUMPTION A1: Let the support of $(P, S)$ be $\Omega_{p} \times \Omega_{s}$. For each $(p, s) \in \Omega_{p} \times \Omega_{s}$, equation (3) holds for some unknown function $G$ and some vector of constants $a_{s}=\left(a_{s 1}, \ldots, a_{s J}\right)$. The function $M(p, s)$ is identified for all $(p, s) \in \Omega_{p} \times \Omega_{s}$.

ASSUMPTION A2: Assume for some $t \in \Omega_{s}$ that $a_{t j}=1$ for $j=1, \ldots, J$.

Assumption A1 essentially just lays out the model. Assumption A2 is a scale normalization. Assumption A2 can be made without loss of generality (as long as $a_{t j}$ is not identically zero), because we can simply redefine the function $G$ to make $a_{t j}=1$, by replacing $G$ with $\widetilde{G}$ defined by $\widetilde{G}(p)=G\left(a_{t 1} p_{1}, \ldots, a_{t J} p_{J}\right)$ and replacing each $a_{s j}$ with $\widetilde{a}_{s j}$ defined by $\widetilde{a}_{s j}=a_{s j} / a_{t j}$. Note, however, that the choice of normalization can affect economic interpretation of the function $G$ and the $a_{s j}$ coefficients. $^{4}$

Our first alternative identifying assumption is the following

ASSUMPTION A3: Assume $G(p)$ is continuously differentiable. Let $m_{j}(p, s)=\partial M(p, s) / \partial p_{j}$

\footnotetext{
${ }^{4}$ In our collective household application, the $a_{s j}$ coefficients are measures of how much each good $j$ is shared (consumed jointly by multiple members) in a household of type $s$. There it will be appropriate to normalize $a_{t j}$ to equal one for singles $t$ (people who live alone), and who therefore cannot be sharing. See Lewbel (2019) for more on the economic implications of scale normalizations.
} 
and let $g_{j}(p)=\partial G(p) / \partial p_{j}$. For any $J$-vector $\alpha=\left(\alpha_{1}, . ., \alpha_{J}\right)$, define the $J$-vector valued function $\zeta(\alpha, p, s)$ as having the elements

$$
\zeta_{j}(\alpha, p, s)=\frac{m_{j}(p, s)}{g_{j}\left(\alpha_{1} p_{1}, \ldots, \alpha_{J} p_{J}\right)} \text { for } j=1, \ldots, J
$$

For each $s \in \Omega_{s}$, assume there exists a $\widetilde{p} \in \Omega_{p}$ such that $A_{s} \widetilde{p} \in \Omega_{p}$ and $\zeta_{j}(\alpha, p, s)$ is a contraction on $a$.

Assumption A3, is a high level assumption, which may therefore be hard to verify in practice. However, in the special case of multiple linear index models, Assumption A3 corresponds to uniquely recovering index coefficients from derivatives of $M$, and so relates to the identification conditions given in Xia (2008) and Donkers and Schafgans (2008).

An alternative to Assumption A3 is Assumption A4, which is more restrictive than A3, but is a much lower level assumption and hence may be simpler to verify in some applications.

ASSUMPTION A4: Assume $\Omega_{p}$ includes a (possibly one sided) neighborhood of zero, and that $G(p)$ is continuously differentiable for all $p$ in that neighborhood of zero. Assume for each $j=1, \ldots, J$ that $\partial G(p) / \partial p_{j}$ (or the corresponding one sided derivatives) does not equal zero when $p=0$.

Assumption A4 exploits how our model simplifies at the point where $p=0$. This is a method of identification that is also used by Matzkin (2003, 2012) and Lewbel and Pendakur (2017). Applying Assumption A4 when $p$ is prices requires the one sided version of Assumption A4, since prices cannot be negative. In practice, this identification would require some probability of observing arbitrarily low prices (so the support of $p$ contains values in the neighborhood of zero). However, both ordinary consumer demand models and collective household models are linearly homogeneous in prices $p$ and total expenditures $y$. Therefore, it is only $p / y$ that needs to include a one sided neighborhood of zero, and the presence of very wealthy consumers can insure that some observed values of $p / y$ are very close to zero.

Define the random vector $V$ by $V=\left(V_{1}, \ldots, V_{J}\right)$ where $V_{j}=a_{s j} P_{j}$. Let $\Omega_{v}$ denote the support of $V$.

LEMMA 1: Let Assumptions A1 and A2 hold. If either Assumption A3 or Assumption A4 also holds then the coefficients $a_{s 1}, \ldots, a_{s J}$ and the function $G(v)$ are point identified for all $v \in \Omega_{v}$ and $s \in \Omega_{s}$. 
The identification in Lemma 1 is what Khan and Tamer (2010) call "thin set" identification. Thin set identification is when identification is based on a measure zero subset of the support of the data. In this example, identification is based either on the point $p$ that makes Assumption A3 hold, or the point $p=0$ for Assumption A4. Either such point is observed with probability zero if $P$ is continuous. The more well known concept of "identification at infinity" as in Chamberlain (1986) and Heckman (1990) is another example of thin set identification. Many of the identification theorems given in Matzkin (2003, 2007, 2012) assume a normalization that otherwise unknown functions take on known values at one point, such as zero. Such normalizations typically imply thin set identification. In practice, estimators of parameters that are only thin set identified will usually converge at slow rates. See Khan and Tamer (2010) and Lewbel (2019) for details regarding thin set identification.

One way to avoid thin set identification is to assume that Assumption A3 holds at a mass point p. Another way would be to assume that Assumption A3 holds for all points $p$ in some convex positive measure subset of $\Omega_{p}$. However, this is an additional strong high level assumption that could be difficult to verify.

To avoid issues associated with thin set identification, we now give a third alternative assumption for obtaining identification. A disadvantage of this identification condition is that it requires a large support assumption on $P$. However, unlike identification at infinity or other thin set identification arguments, here the large support assumption is only needed to avoid the presence of boundary terms in a change of variables argument.

For a given function $\psi_{j}$, define $c_{j}$ by

$$
c_{j}=\int_{0}^{\infty} \ldots \int_{0}^{\infty} \psi_{j}[G(p)] p_{1}^{-1} \ldots p_{j-1}^{-1} p_{j+1}^{-1} \ldots p_{J}^{-1} d p_{1} \ldots d p_{J}
$$

ASSUMPTION A5: Assume $\Omega_{p}$ is the positive orthant. $G(p)$ is continuous for all $p \in \Omega$. All $a_{s j}$ are positive. For each $j \in\{1, \ldots, J\}$, we can find a continuous function $\psi_{j}$ such that the constant $c_{j}$ defined by equation (4) exists, is finite, and non-zero.

Having $\Omega_{p}$ be the positive orthant is the large support assumption. As noted above for Assumption $\mathrm{A} 4$, when $p$ is prices we can replace $p$ with $p / y$, so very low and very high incomes (corresponding to extreme values of $y$ ) can generate very low and very high prices. However, large 
support also requires that extremes in relative prices of goods be possible.

The assumption that all $a_{s j}$ are positive is testable, using the estimated average derivatives with respect to $p_{j}$ of $M(p, s)$ relative to average derivatives of $M(p, t)$ (recalling that by Assumption A2, all $a_{t j}$ equal one). In our empirical application, the $a_{s j}$ coefficients will be sharing parameters that are positive by construction.

Assumption A5 says we can find a continuous function $\psi_{j}$ that makes the integral given by equation (4) convergent. Note that $G(p)$ is identified by $G(p)=M(p, t)$, so knowing $G$, the assumption is that we can construct a continuous function $\psi_{j}$ that goes to zero sufficiently quickly whenever any element of $P$ goes to zero, and grows sufficiently slowly, or not at all, when any element of $P$ goes to infinity. A simple example that satisfies Assumption A5 is where $G(p)$ equals some strictly monotonic transformation of $\prod_{j=1}^{J} p_{j} e^{-b_{j} p_{j}}$ for positive constants $b_{j}\left(\psi_{j}\right.$ would then be the inverse of that monotonic transformation). A similar construction to Assumption A5 appears in Lewbel and Pendakur (2017). However, their application involves stronger conditions than the above assumptions, because they identify distributions of random coefficients rather than constants.

LEMMA 2: If Assumptions A1, A2, and A5 hold, then the coefficients $a_{s 1}, \ldots, a_{s J}$ and the function $G(v)$ are point identified for all $v \in \Omega_{v}$ and $s \in \Omega_{s}$.

Both Lemmas 1 and 2 have proofs by construction, so semiparametric estimators could be readily constructed by mimicking the steps of either proof. Combining Lemmas 1 and 2, and separately considering the scale normalization of Assumption A2 gives us our first identification theorem.

THEOREM 1: Let Assumption A1 hold. If either Assumption A3, A4, or A5 also holds, then the relative coefficients $a_{s 1} / a_{t 1}, \ldots, a_{s J} / a_{t J}$ are point identified for all $v \in \Omega_{v}, s \in \Omega_{s}$, and $t \in \Omega_{s}$. If Assumption A2 also holds then the coefficients $a_{s 1}, \ldots, a_{s J}$ and the function $G(v)$ are point identified for all $v \in \Omega_{v}$ and $s \in \Omega_{s}$.

In practice, for estimation it may be unnecessary to know which identifying assumptions hold; it can suffice to just assume that any one of them hold. For example, suppose $M$ is defined by a conditional expectation, so $M(p, s)=E(Y \mid P=p, S=s)$. Then we could consider estimating the parameters $a_{s j}$ and function $G$ by, e.g., Ai and Chen's (2003) sieve GMM, based on conditional moments $E\left(Y-G\left(A_{s} p\right) \mid P=p, S=s\right)=0$. Regularity conditions simply assume identification based on conditional moments, along with assumptions on the data generating process. Note, 
however, that the rate of convergence of the resulting estimator may depend on which identifying assumptions hold.

\section{The Collective Household Model of Consumption}

We briefly summarize Pareto efficient collective household consumption models here, focusing on the BCL model. Until recently, virtually all collective household models divided goods into two types: private goods, that are individually consumed by household members, and public goods, that are jointly consumed by all household members. The BCL model generalizes this earlier literature by allowing goods to be partially shared. An example is something like gasoline use, which is shared, or jointly consumed, when household members travel together in a car, and is privately consumed when a household member drives alone. Each $a_{s j}$ parameter in this model is a measure of how much good $j$ is jointly consumed by the members of a household having characteristics $s$. As noted earlier, by analogy with the model of Barten (1964), these $a_{s j}$ parameters are called Barten coefficients or Barten scales.

A household consists of $K$ members. Let subscript $j$ index goods and superscript $k$ index household members. Let $z$ denote the vector of continuous quantities of goods purchased by the household. In the BCL model, a Pareto efficient household facing prices $p$, with characteristics $s$, and total expenditures (budget) $y$, solves the following optimization problem

$$
\underset{x^{1}, \ldots, x^{K}}{\max } \sum_{k=1}^{K} \mu_{s}^{k}(p / y) U_{s}^{k}\left(x^{k}\right)
$$

such that $z=A_{s} x, x=\sum_{k=1}^{K} x^{k}$, and $p^{\prime} z=y$

$U_{s}^{k}$ is member $k$ 's utility function. The model allows household members to have different preferences. $\mu_{s}^{k}$ is the so-called "Pareto weight" of each member. the higher a member's Pareto weight, the more that member's tastes affect the household's purchases. $p^{\prime} z \leq y$ is the household's budget constraint. The quantity vector $x^{k}=\left(x_{1}^{k}, \ldots, x_{J}^{k}\right)$ is the vector of member $k$ 's "private good equivalents" of goods, that is, the indifference curve member $k$ attains in the household is the indifference curve that he or she would attain, if while living alone, her or she had consumed the vector $x^{k}$. The vector $x$ is the sum of the private good equivalents for all members. The square diagonal matrix $A_{s}$, which contains the terms $a_{s j}$, summarizes the household's "consumption technology function," which converts purchased goods $z$ into private equivalents $x$ via sharing and 
jointness of consumption. For each good $j$, the household sets $x_{j} / z_{j}$ equal to $1 / a_{s j}$. Having $a_{s j}=1$ means good $j$ is not jointly consumed at all (this would be the case if all goods were private, or if the individual lived alone), otherwise the smaller $a_{s j}$ is, the more good $j$ is consumed jointly.

BCL show ${ }^{5}$ that the household's demand functions arising from the above optimization have the form

$$
\frac{p_{j} z_{j}}{y}=\omega_{j}(p, s, y)=\sum_{k=1}^{K} \widetilde{\eta}_{s}^{k}(p, y) h_{j}^{k}\left(a_{s 1} p_{1}, \ldots, a_{s J} p_{J}, \widetilde{\eta}_{s}^{k}(p, y) y\right) \quad j=1, \ldots, J
$$

The function $\omega_{j}(p, s, y)$ is the household's budget share demand function for good $j . h_{j}^{k}$ is household member $k$ 's demand function for good $j$, based on member $j$ 's utility function. $\widetilde{\eta}_{s}^{k}(p, y)$ is member $k$ 's resource share, that is, the fraction of the household's total budget $y$ that is spent on buying private good equivalents consumed by member $j$.

We make the following modifications to the BCL model with Barten consumption technology:

1. BCL assumes the $h_{j}^{k}$ functions are known, while we mostly do not. ${ }^{6}$ In their data, BCL identify all of the $h_{j}^{k}$ functions by using data from singles (individuals living alone), and assume these demand functions do not change when people cohabit. Among other implications, this means BCL cannot include children in their model, while we can. We will identify most or all of the $h_{j}^{k}$ functions along with the rest of the model.

2. We assume the household has some private, assignable goods. A private assignable good is a good that is only consumed by (and provides utility for) one, known, household member. In our empirical application, only two private assignable goods are needed for identification, but we have three in our data: men's, women's, and children's clothing and shoes. We also assume that resource share functions do not depend on $y$. These restrictions are commonly assumed in the collective household literature. Examples include Lewbel and Pendakur (2008), Couprie, Peluso, and Trannoy (2010), Bargain and Donni (2009, 2012), Lise and Seitz (2011), and Dunbar, Lewbel, and Pendakur (2013), Penglase (2019), and Calvi (2020). Many of these papers also use clothing as private assignable goods. Other researchers provide direct empirical evidence supporting these assumptions, including Menon, Pendakur, and Perali (2012) and Cherchye, De Rock, Lewbel, and

\footnotetext{
${ }^{5} \mathrm{BCL}$ derive this equation for $K=2$, and do not include the $s$ subscript, but these extensions to their theory are straightforward.

${ }^{6}$ Our results showing identification of relative resource shares and relative Barten consumption technology coefficients assume the $h_{j}^{k}$ functions are not known at all. Our results showing full identification of all features of the model assume that, of the $J$ times $K$ total number of $h_{j}^{k}$ functions, just $K-1$ of them are known (i.e., can be identified from singles data). In particular, none of the children's functions need to be known.
} 
Vermeulen (2015) (see also Bonke and Browning 2011).

With these assumptions, we can write the resulting BCL demand functions as

$$
\frac{p_{j} z_{j}}{y}=\omega_{j}(p, s, y)=\sum_{k=1}^{K} \eta_{s}^{k}\left(A_{s} p\right) h_{j}^{k}\left(A_{s} p, \eta_{s}^{k}\left(A_{s} p\right) y\right)
$$

where resource shares now have the simpler form $\eta_{s}^{k}\left(A_{s} p\right)$. For each member $k$ who has a private assignable good, we will index that good as good $k$. The household demand functions of the private assignable good simplify to

$$
\frac{p_{k} z_{k}}{y}=\omega_{k}(p, s, y)=\eta_{s}^{k}\left(A_{s} p\right) h_{k}^{k}\left(A_{s} p, \eta_{s}^{k}\left(A_{s} p\right) y\right)
$$

It will be important for some later results to note that utility maximization results in demand functions that are homogeneous of degree zero in $p$ and $y$ (this is known as the absence of money illusion), which means that equation (7) can be equivalently written as

$$
\frac{p_{j} z_{j}}{y}=\omega_{j}(p, s, y)=\sum_{k=1}^{K} \eta_{s}^{k}\left(A_{s} \frac{p}{y}\right) h_{j}^{k}\left(A_{s} \frac{p}{y}, \eta_{s}^{k}\left(A_{s} \frac{p}{y}\right)\right)
$$

and similarly for equation (8).

\section{Identification of the Collective Household Model}

We now consider identification of the collective household model given by equations (7) and, for private assignable goods, (8). As with Theorem 1, we present a few alternative sets of identifying assumptions each with relative advantages and disadvantages depending on context.

ASSUMPTION B1: Household budget share demand functions $\omega_{j}(p, s, y)$ for $j=1, \ldots, J$ are given by equation (7), which for private assignable goods reduces to equation (8), where for all $(p, s, y) \in \Omega_{p} \times \Omega_{s} \times \Omega_{y}$, the functions $h_{j}^{k}(p, y)$ and $\eta_{s}^{k}(p)$ are positive and continuous for each member $k=1, \ldots, K$, and each $s \in \Omega_{s}$. The consumption technology constants $a_{s j}$ are bounded and strictly positive for each $s \in \Omega_{s}$ and each good $j$.

Assumption B1 essentially lays out the collective household model as discussed in the previous section. The continuity conditions follow naturally from smooth utility and household bargaining 
or social welfare functions. Similarly, having the Barten coefficients $a_{s j}$ be bounded and positive must hold because it is impossible for every member of a household to consume more than the total purchased quantity of a good (even if it is completely shared), and it is impossible to consume negative quantities of goods.

Our first goal is to identify relative values of the Barten constants $a_{s 1}, \ldots, a_{s J}$. We cannot immediately apply Theorem 1 (taking $G$ to be any of the household demand functions $\omega_{j}$ ) because of the presence of the resource share functions $\eta_{s}^{k}$ which vary by $s$. We therefore will first construct a function $G$ out of either one or two demand functions $\omega_{j}$ using Theorem 2 below, and then apply Theorem 1 to the result.

Assumptions B2, B3, B4, B5, and B6 below are alternatives; only one needs to hold for Theorem 2. Analogous to the Assumptions for Theorem 1, some of these assumptions (B2 and B3) entail thin set identification, while others (B4 and B5) require large support. These assumptions also vary in how many private assignable goods they require: B2, B4 and B6 each require one private assignable good, B3 requires two, and B5 does not require any.

By providing a range of alternative assumptions, we can obtain identification with a wide variety of different demand functions. Note that the class of demand functions in Assumption B6 are widely used in the empirical literature (see, e.g., Gorman 1981 or Banks, Blundell, and Lewbel 1997). The demand functions we use in our empirical application satisfy Assumptions B3 and B6. These assumptions are discussed further in the next section.

ASSUMPTION B2: Assume that $\Omega_{y}$ includes a one sided neighborhood of zero. Assume there exists a private assignable good $j$. Assume that, for all $(p, s) \in \Omega_{p} \times \Omega_{s}$ (except possibly on a subset of measure zero), the function $M(p, s)$ defined by the following equation is finite, nonzero, and has nonzero derivatives with respect to $p$.

$$
M(p, s)=\lim _{y \rightarrow 0} \frac{\partial \omega_{j}(p, s, y) / \partial y}{\omega_{j}(p, s, y)^{2}}
$$

ASSUMPTION B3: Assume that $\Omega_{y}$ includes a one sided neighborhood of zero. Assume there exist two private assignable goods $j$ and $\widetilde{j}$. Assume that, for all $(p, s) \in \Omega_{p} \times \Omega_{s}$ (except possibly on a subset of measure zero), the function $M(p, s)$ defined by the following equation is finite, nonzero, 
and has nonzero derivatives with respect to $p$.

$$
M(p, s)=\lim _{y \rightarrow 0} \frac{\partial \omega_{j}(p, s, y) / \partial y}{\omega_{j}(p, s, y)^{2}} / \frac{\partial \omega_{j}(p, s, y) / \partial y}{\omega_{\tilde{j}}(p, s, y)^{2}}
$$

ASSUMPTION B4: Assume that $\Omega_{y}$ includes $(0, \infty)$. Assume there exists a private assignable good $j$. Assume that for all $(p, s) \in \Omega_{p} \times \Omega_{s}$ (except possibly on a subset of measure zero), there exists a real constant $c$ such that the function $M(p, s)$ defined by the following equation is finite, and has nonzero derivatives with respect to $p$.

$$
M(p, s)=\int_{0}^{\infty}\left[\omega_{j}(p, s, y)\right]^{c} y^{c-1} d y
$$

ASSUMPTION B5: Assume that $\Omega_{y}$ includes $(0, \infty)$. Assume there exists a good $j$ such that, for all $(p, s) \in \Omega_{p} \times \Omega_{s}$ (except possibly on a subset of measure zero), the function $M(p, s)$ defined by the following equation is finite, and has nonzero derivatives with respect to $p$.

$$
M(p, s)=\int_{0}^{\infty} \omega_{j}(p, s, y) d y
$$

ASSUMPTION B6: Assume there exists a private assignable good $k=j$ for each household member $j$ such that $h_{j}^{k}(p, y)=\sum_{\ell=0}^{L} \psi_{j \ell}^{k}(p)(\ln (y))^{\ell}$ for some positive integer $L$ and functions $\psi_{j \ell}^{k}$. Define $\xi(p, s)=\left|\partial^{L} \omega_{j}(p, s, y) / \partial(\ln y)^{L}\right|^{-1}$. Assume the function $M(p, s)$ defined by the following equation is finite, and has nonzero derivatives with respect to $p$.

$$
M(p, s)=\xi(p, s) \omega_{j}(p, s, \xi(p, s))
$$

THEOREM 2: Let Assumption B1 hold. If either Assumption B2, B3, B4, B5, or B6 also holds then there exists a function $G(p)$, with nonzero derivatives for all $p \in \Omega_{p}$ (except possibly on a subset of measure zero), such that, for all $s \in \Omega_{s}, M(p, s)=G\left(A_{s} p\right)$.

COROLLARY 1: Let Assumption B1 hold. If either Assumption B2, B3, B4, B5, or B6 also holds, and if $G\left(A_{s} p\right)$ from Theorem 2 satisfies Assumption A1 and either Assumption A3 or A4 or A5, then $a_{s j} / a_{t j}$ is identified for every $s \in \Omega_{s}$, every $t \in \Omega_{s}$, and every $j \in\{1, \ldots, J\}$.

Theorem 2 shows that equation (3) holds, and so Theorems 1 and 2 can be combined as in Corollary 1. Corollary 1 shows that all the relative Barten scales $a_{s j} / a_{t j}$ are identified. Note that 
in Theorem 2 we do not assume a scale normalization, i.e., we do not yet impose Assumption A2. Later we will use data on singles living alone, who therefore cannot share, to properly scale each $a_{s j}$.

A notable feature of Theorem 2 is that it gets identification from the demand functions of just one or two goods that the household consumes. Since we can estimate household demand functions for many goods, we can expect the Barten scales to be greatly over identified in practice. Also, these results do not require monotonicity of demands, which is useful because empirically the effects of both $p$ and $y$ on budget shares can change signs.

Another feature of Theorem 2 is that the only constraint it places on the resource share functions $\eta_{s}^{k}(p)$ is the minimal regularity given in Assumption B1. In particular, Assumptions B2 to B6 place no additional constraints on the resource share functions, as can be seen by replacing each $\eta_{s}^{k}(p)$ with any other suitably bounded regular function $\widetilde{\eta}_{s}^{k}(p)$ in the proof of Theorem 2.

To illustrate some of the above alternative identifying assumptions, consider the general case of private assignable demand functions that are polynomials in $y$. More precisely, let good $k$ be assignable to member $j$, and assume the function $h_{j}^{k}$ is an arbitrary $L$ 'th order polynomial in $y$, so

$$
\omega_{j}(p, s, y)=\eta_{s}^{j}\left(A_{s} p\right) \sum_{\ell=0}^{L} \widetilde{h}_{\ell j}\left(A_{s} p\right) \eta_{s}^{j}\left(A_{s} p\right)^{\ell} y^{\ell}
$$

for some functions $\widetilde{h}_{\ell j}$. We now give closed form expressions for what the resulting $M(p, s)$ functions will equal, to which we can then apply Theorem 1. First, applying Assumption B2 gives

$$
M(p, s)=\widetilde{h}_{1 j}\left(A_{s} p\right) / \widetilde{h}_{0 j}\left(A_{s} p\right)^{2}
$$

while applying Assumption B3 gives

$$
M(p, s)=\frac{\widetilde{h}_{1 j}\left(A_{s} p\right) / \widetilde{h}_{0 j}\left(A_{s} p\right)^{2}}{\widetilde{h}_{1 \widetilde{j}}\left(A_{s} p\right) / \widetilde{h}_{0 \tilde{j}}\left(A_{s} p\right)^{2}}
$$

To provide one more example, consider demands that are polynomials in $\ln y$ instead of in $y$. Then we can apply Assumption B6, which yields

$$
M(p, s)=\frac{\sum_{\ell=0}^{L} \psi_{j \ell}^{j}\left(A_{s} p\right)\left(-\ln \left|\psi_{j L}^{j}\left(A_{s} p\right)\right|\right)^{\ell}}{\left|\psi_{j L}^{j}\left(A_{s} p\right)\right|}
$$


Given identification of the Barten technology, our next goal is identification of the relative values of the resource share functions $\eta_{s}^{k}$. Define the vector $\phi_{s t}(p)$ to be the vector of elements $\phi_{s t j}\left(p_{j}\right)$ defined by

$$
\phi_{s t j}\left(p_{j}\right)=\frac{p_{j}}{a_{s j} / a_{t j}}
$$

for some $t \in \Omega_{s}$ chosen by the econometrician.

ASSUMPTION C1: Assume that $\Omega_{y}$ includes a one sided neighborhood of zero, that there exists a private good $j$ that is assignable to some household member $k$, and for that good $j$ the budget share function $\omega_{j}\left(s, \phi_{s t}(p), 0\right)$ is finite and nonzero for all $(p, s) \in \Omega_{p} \times \Omega_{s}$.

ASSUMPTION C2: Assume that $\Omega_{y}$ includes $(0, \infty)$, that there exists a private good $j$ that is assignable to some household member $k$, and for that good $j$, for all $(p, s) \in \Omega_{p} \times \Omega_{s}$, the function $m(p, s)$ defined by the following equation is finite and nonzero for some real constants $c_{1}$ and $c_{2}$ where $c_{2} \neq c_{1}-1$ and $c_{1} \neq 0$.

$$
m(p, s)=\int_{0}^{\infty}\left[\omega_{j}\left(s, \phi_{s t}(p), y\right)\right]^{c_{1}} y^{c_{2}} d y
$$

THEOREM 3: Let the Assumptions of Corollary 1 hold for some $s \in \Omega_{s}$ and let them also hold replacing $s$ with some other value $r \in \Omega_{s}$. If in addition either Assumption C1 or C2 holds, then the relative values of resource shares $\eta_{s}^{k}\left(A_{t} p\right) / \eta_{r}^{k}\left(A_{t} p\right)$ are identified for all $p$ such that $\left(a_{s 1} \phi_{s t 1}\left(p_{1}\right), \ldots, a_{s J} \phi_{s t J}\left(p_{J}\right)\right)$ and $\left(a_{r 1} \phi_{r t 1}\left(p_{1}\right), \ldots, a_{r J} \phi_{r t J}\left(p_{J}\right)\right)$ lie in $\Omega_{p}$. If $\Omega_{p}$ is the positive orthant, then $\eta_{s}^{k}\left(A_{t} p\right) / \eta_{r}^{k}\left(A_{t} p\right)$ is identified for all $p \in \Omega_{p}$.

The classical identification result in the collective household literature discussed earlier, that resource shares are identified up to unknown location, is equivalent in our model to identifying $\eta_{s}^{k}\left(A_{s} p\right) / \eta_{r}^{k}\left(A_{r} p\right)$ for $r, s \in \Omega_{s}$. Theorems 2 and 3 together generalize this classical result to the BCL model where goods can be partly shared. Moreover, these theorems give explicit conditions for point identification of these relative shares, rather than just generic identification.

One limitation of Theorem 3 is that, if $\Omega_{p}$ is not the positive orthant, there could exist values of $p$ for which identification of the relative resource shares is not shown. However, the identification 
in Theorem 3 uses just the demand functions of at most two goods for each household member. Since the demand functions for many goods are observed, as with Theorem 2 we can in general expect substantial overidentification, based on information using multiple goods that the household consumes. Another limitation of Theorem 3 relative to the earlier generic identification literature (albeit a restriction with a great deal of theoretical precedent and empirical support, as discussed earlier) is our assumed restriction that the resource share function not depend on $y$.

Identification of relative values of resource shares does not suffice to answer some questions of economic significance. In particular, as stressed by Dunbar, Lewbel, and Pendakur (2013), identification of poverty rates and of relative bargaining power of household members requires identifying the levels of resource shares, not just their relative values.

Therefore, for the last part of this section, we consider using additional information to obtain identification of the entire model, including levels of resource shares, levels of Barten scales, and the demand functions of each household member.

ASSUMPTION D1: For each household member $k=1, \ldots, K-1$ assume there exists a private assignable good, which without loss of generality denote as good $k$. Assume that we observe singles of member type $k$ living alone, and that the demand functions for these assignable goods, the functions $h_{k}^{k}$, are the same whether a member of type $k$ is in a collective household or not.

To identify the levels of resource shares, BCL assume that we can observe singles of every household member type $k=1, \ldots, K$, and that their demand functions for all goods remain the same whether inside or outside a collective household. Assumption D1 considerably weakens the BCL assumptions, by only requiring that we observe singles of $K-1$ member types, and that only one good for each type needs to have a demand function that doesn't change when in a collective household. $^{7}$ However, Assumption D1 is stronger than BCL in one sense, which is that it requires existence of some private assignable goods.

THEOREM 4: Let the Assumptions of Corollary 1 hold for all $s \in \Omega_{s}$, and let Assumption D1 hold. Let either Assumption C1, C2, or B6 hold. Then the entire model is identified.

What we mean by the entire model being identified in Theorem 4 is that all the Barten scales

\footnotetext{
${ }^{7}$ Note that when we say the demand function doesn't change, we only mean the functions $h_{k}^{k}$ (which are derived from individual $k$ 's utility function) stay the same. Actual consumption quantities as functions of prices and total expenditures will differ, because within the collective household, each function $h_{k}^{k}$ is evaluated at shadow prices and a shadow budget, rather than market prices and the single's actual budget.
} 
$a_{s j}$, all the resource share functions $\eta_{s}^{k}(p)$, and all the demand functions $h_{j}^{k}(p, y)$ are identified.

In our application, we have $K=3$ : men, women, and children. So for Theorem 4 we need $K-1=2$ of these three to have an identifiable private assignable good. In our case we observe men's clothes and women's clothes, which have demand functions that we identify from single men and single women. In this example we do not need to observe or identify any child assignable goods, which is very useful because we would not expect to observe households consisting of children living alone (the original BCL model did not include children because, unlike the present paper, it did not overcome this obstacle to identification with children). We also observe children's clothing in our application, but we of course can only identify the demand for children's clothing within the collective household, not as a single.

\section{$6 \quad$ An Applied Model and Identifying Assumptions}

We have proven identification of the model where all the component functions are nonparametric. However, these functions are high dimensional, so nonparametric estimation is not practical with modest sample sizes. We will therefore instead estimate a parametric model, but make use of relatively flexible functional forms. In this section we lay out our parametric model, and verify its compatibility with our identifying assumptions.

Our model starts with a utility derived functional form for the budget shares of individuals. We specify individual preferences using the Quadratic Almost Ideal Demand System (QUAIDS) developed by Banks et al. (1997).

In our application the number of goods $J=6$. Let $h$ index households, and let $k$ denote a household member. Household member types $k$ are $f$ for female, $m$ for male, and $c$ for children. For member $k$ of household $h$, let $\omega^{j h k}$ denote the fraction of member $k$ 's total resources in the household that he/she spends on good $j$, and let $\omega^{h k}$ be the $J$-vector of budget shares $\omega^{j h k}$ for $j=1, \ldots, J$. Note that we can only observe $\omega^{j h k}$ in households $h$ that have just one member $k$ (since for those households observed purchased budget shares equal the shares consumed by member $k$ ).

The QUAIDS demand system, for a single individual of type $k$, living in the household $h$, takes the $J$-vector form

$$
\omega^{h k}\left(\frac{p}{y^{h}}\right)=\alpha^{h k}+\Gamma^{k} \ln p+\beta^{h k}\left[\ln \left(y^{h}\right)-c^{h k}(p)\right]+\frac{\lambda^{k}}{b^{h k}(p)}\left[\ln \left(y^{h}\right)-c^{h k}(p)\right]^{2}
$$


Here $b^{h k}(p)$ and $c^{h k}(p)$ are price indices defined as

$$
\begin{gathered}
\ln \left[b^{h k}(p)\right]=(\ln p)^{\prime} \beta^{h k}, \\
c^{h k}(p)=c_{0}^{h k}+(\ln p)^{\prime} \alpha^{h k}+\frac{1}{2}(\ln p) \Gamma^{k \prime} \ln p,
\end{gathered}
$$

$\alpha^{h k}, \beta^{h k}$, and $\lambda^{k}$ are $J$-vectors of preference parameters, $\Gamma^{k}$ is a $J \times J$ matrix of preference parameters $\gamma_{j j^{\prime}}^{k}$ having rank $J-1$, and $c_{0}^{h k}$ is a scalar parameter which we set to equal to zero based on the insensitivity reported in Banks et al. (1997). By definition, budget shares must add up to one, i.e., $1_{J}^{\prime} \omega^{h k}=1$ for all $p / y$, where $1_{J}$ is a $J$-vector of ones. This, in turn, implies that $1_{J}^{\prime} \alpha^{h k}=1$, $1_{J}^{\prime} \beta^{h k}=0,1_{J}^{\prime} \lambda^{k}=0$, and $\Gamma^{k \prime} 1_{J}=0_{J}$, where $0_{J}$ is a $J$-vector of zeros. Slutsky symmetry requires that $\Gamma^{k}$ be a symmetric matrix.

As the indices above show, we let the parameter vectors $\alpha^{h k}$ and $\beta^{h k}$ vary by household $h$ as well as by individual $k$. In particular, we specify these parameter vectors by

$$
\begin{aligned}
& \alpha^{h k}=\alpha_{0}^{k}+\sum_{m=1}^{M_{\alpha}} \alpha_{m}^{k} d_{m, \alpha}^{h k} \\
& \beta^{h k}=\beta_{0}^{k}+\sum_{m=1}^{M_{\beta}} \beta_{m}^{k} d_{m, \beta}^{h k},
\end{aligned}
$$

where $d_{m, \alpha}^{h k}$ and $d_{m, \beta}^{h k}$ are observed demographic characteristics, and $M_{\alpha}$ and $M_{\beta}$ are the number of such covariates we observe. Each $\alpha^{h k}$ and $\beta^{h k}$ is a $J$-vector, which from the above adding up restrictions must satisfy $1_{J}^{\prime} \alpha_{0}^{k}=1,1_{J}^{\prime} \alpha_{m}^{k}=0$ for $m=1, \ldots, M_{\alpha}$, and $1_{J}^{\prime} \beta_{m}^{k}=0$ for $m=0, \ldots, M_{\beta}$.

In our application $d_{m, \alpha}^{h k}$ consists of 7 region dummies and the age of member $k$, making $M_{\alpha}=8$, while $d_{m, \beta}^{h k}$ is an indicator for homeownership, so $M_{\beta}=1$. Taken together, we have 17 preference parameters for each of $J-1=5$ distinct equations, yielding a total of 85 parameters for each type of individual $k$. Note that the model for households with more than one member will also have additional parameters associated with resource shares and Barten scales.

We parameterize each household member's resource share with the functional form

$$
\eta^{f}=\frac{\exp \left(\delta^{f^{\prime}} s\right)}{1+\exp \left(\delta^{f^{\prime}} s\right)+\exp \left(\delta^{m^{\prime}} s\right)},
$$




$$
\eta^{m}=\frac{\exp \left(\delta^{m^{\prime}} s\right)}{1+\exp \left(\delta^{f^{\prime}} s\right)+\exp \left(\delta^{m^{\prime}} s\right)},
$$

where $f$ denotes female and $m$ denotes male, and the children's resource share is $1-\eta^{f}-\eta^{m}$. If there are no children in the household, then

$$
\eta^{f}=\frac{\exp \left(\delta^{f^{\prime}} s\right)}{1+\exp \left(\delta^{f^{\prime}} s\right)}
$$

and the husband's share is $1-\eta^{f}$. This is a commonly used functional form for imposing the constraint that resource shares are positive and sum to one.

In the collective household literature, variables $s$ that affect resource shares are called "distribution factors." See, e.g., Browning, Bourguignon, Chiappori, and Lechene (1994), Browning and Chiappori (1998). In our model, these $s$ variables also affect the Barten parameters $a_{s j}$. Lewbel and Pendakur (2019) call variables that affect both resource shares and sharing, "cooperation factors." The vector $s$ in our application consists of the difference in age between the wife and husband, the difference in log income between the wife and husband ${ }^{8}$, number of children, the minimum age of children less 5 , the age of the wife less 39 (the average age of wives in the sample), and indicators of whether the wife has some college education, and whether the husband has some college education.

With the Barten consumption technology, we obtain the following expression for the budget shares of couples with one to four children:

$$
\begin{gathered}
\omega_{j}^{h}\left(p, s^{h}, y^{h}\right)=\eta_{s}^{h f} \omega_{j}^{h f}\left(\frac{A_{s} p}{\eta_{s}^{h f} y}\right)+\eta_{s}^{h m} \omega_{j}^{h m}\left(\frac{A_{s} p}{\eta_{s}^{h m} y}\right) \\
\quad+\left(1-\eta_{s}^{h f}-\eta_{s}^{h m}\right) \omega_{j}^{h c}\left(\frac{A_{s} p}{\left(1-\eta_{s}^{h f}-\eta_{s}^{h m}\right) y}\right) .
\end{gathered}
$$

Couples with no children have the same expression but with $\omega^{h_{j}^{c}}$ (the budget share demand function of children $c$ for good $j$ ) set equal to zero.

We now consider consistency of this specification with our identification Theorems. As discussed earlier, Assumption B1 follows directly from the general specification of collective household models.

\footnotetext{
${ }^{8}$ Income is a continuous variable in the dataset. In our theoretical section, we assume $s$ to be discrete. In the empirical section, we try discretizing household income with ten income brackets. The results on sharing rule parameters and Barten scales do not change much.
} 
We next require one of Assumptions B2, B3, B4, B5, or B6 to hold. In our demand model, Assumption B6 holds with $\mathrm{L}=2$. Alternatively, it can be directly verified that Assumption B3 holds as well. Either suffices for Theorem 2.

Next consider Corollary 1. This entails identification of relative values of $A_{s}$ from $M(p, s)$. This is most readily satisfied with $M(p, s)=c^{h k}\left(A_{s} p\right)$. Applying Assumption A3 we get that $\partial M(p, s) / \partial p_{j}$ at $p=1$ is $\sum_{\tilde{j}=1}^{J} \gamma_{j j^{\prime}}^{k} a_{s j}$ for $j=1, \ldots, J$, from which we can recover the relative values of the $a_{s j}$. Note that the matrix of parameters $\gamma_{j j^{\prime}}^{k}$ is identified from variation in $p$.

Finally, consider Theorems 3 and 4. Assumption C1 is in some ways a mild restriction, since it only requires that budget shares, which should lie between zero and one, stay well bahaved even when $y$ goes to zero. However, some popular functional forms, including our QUAIDS model, violate this assumption, because it's a polynomial in $\ln y$. The demand functions here do not satisfy either Assumption $\mathrm{C} 1$ or $\mathrm{C} 2$, and so Theorem 3 identifying relative resource shares does not apply. However, in this case we do not need Theorem 3, because we satisfy the assumptions of Theorem 4, and Theorem 4 identifies the entire model. In particular, as discussed earlier, we satisfy Corollary 1 and Assumption B6, and we observe the demand functions of a private assignable good, clothing, for men and for women.

\section{Empirical Application}

\subsection{Japanese Expenditure Data}

We use Japanese household expenditure and demographic data from the Keio Household Panel Survey (KHPS) and the Japan Household Panel Survey (JHPS). ${ }^{9}$ The survey instructions are, "Enter the amount your household spent on each of the following living expenditures last month (January)." The expenditure categories that we include in this paper are food (at-home or eating-out and school lunches), utilities, clothing and shoes, transportation, communication, and entertainment, giving us a total of $J=6$ different aggregate goods.

The consumption data separately reports household expenditures (in January) on clothing and

\footnotetext{
${ }^{9}$ These data were made available to us by the Panel Data Research Center at Keio University. The KHPS has been implemented continuously since 2004, and consists of 4,000 households and 7,000 individuals nationwide. An additional survey on a cohort of about 1,400 households and 2,500 individuals was initiated in 2007. In 2009, the Panel Data Research Center at Keio University began implementing the JHPS, a new survey targeting 4,000 male and female subjects nationwide in parallel with the KHPS. The survey questionnaires cover comprehensive topics such as household structure, individual attributes, academic background, employment or education status, distribution of living hours, and matters related to cohabitation with parents.
} 
shoes for the household head, spouse(s), and children. The sum of expenditures on clothing and shoes for each household member type (men, women, and children) are our private assignable goods. Note that while the data include assignables for all $K=3$ types of household members, our identification theory only requires observation of $K-1=2$ assignable goods. This provides over identifying information.

We select households (single men, single women, and married couples) according to the following criteria: (1) single women and men are restricted to be between 22 to 65 years old; (2) couples with children aged 15 or over are excluded (since adult clothing purchases could be consumed by older children); (3) households with members as students are excluded; (4) for married couples, households with members over 50 are excluded; (5) observations where expenditures on four or more of the six goods is zero are excluded; and (6) to mitigate the possible effects of outliers, we trim the samples with respect to key variables (the budget share of each aggregate good and log real total expenditure) by dropping observations in the lower and upper 1 percentile. After applying these criteria, we are left with a sample consisting of 276 single women, 357 single men, and 1068 married couples having from zero to four children.

Price data comes from the 2015 based Consumer Price Index (CPI) from e-sTat, the portal site of official statistics of Japan. The detailed construction of price indexes for each aggregate good is reported in Appendix B of the Supplemental Appendix.

\subsection{The Estimator for Singles}

The demand functions for households $h$ consisting of just a single man or a single woman are given by equation (10). Such households have either $k=f$ if the household $h$ is a single woman or $k=m$ if the household $h$ is a single man. In this subsection we describe how these demand functions for singles are estimated. The demand functions and associated estimators for households consisting of multiple members are given in the next subsection.

For households $h$ consisting of singles, we append a $J$-vector valued additive error term $U^{h k}$ (consisting of elements $U^{j h k}$ ) to equation (10). ${ }^{10}$ We assume that $U^{h k}$ are uncorrelated across households. Adding up requires $1_{J}^{\prime} U^{h k}=0$, which implies that nonzero correlations must exist among the elements of each $U^{h k}$, that is, within households across goods $j$. Budget share demand equations are estimated using GMM, allowing for arbitrary correlations in the errors across goods.

\footnotetext{
${ }^{10}$ Additive errors can either be rationalized as measurement errors in budget shares, or by imposing restrictions on preference heterogeneity as in Lewbel (2001).
} 


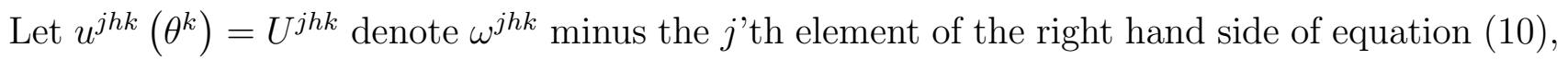
where $\theta^{k}$ is the vector of all the parameters in that equation. Note that $u^{j h k}\left(\theta^{k}\right)$ is implicitly a function of $\omega^{j h k}$ and of all the regressors in the model. The moments used for GMM estimation take the form $E\left(u^{j h k}\left(\theta^{k}\right) \tau^{h k}\right)=0$, with $\tau^{h k}$ being a vector of covariates as defined below. To impose the adding-up constraints we apply the standard practice of dropping one demand equation, and we recover the estimated parameters for that last equation using the adding-up constraints. The choice of which demand equation to drop is numerically irrelevant, because by the adding-up constraints, the parameters of the dropped equation are all deterministic functions of the parameters in the remaining equations. The full set of moments for estimating the model of singles of type $k$ is therefore $E\left(u^{j h k}\left(\theta^{k}\right) \tau^{h k}\right)=0$ for $j=1, \ldots, J-1$. Letting $u^{h k}\left(\theta^{k}\right)$ be the $J-1$ vector of elements $u^{j h k}\left(\theta^{k}\right)$ for $j=1, \ldots, J-1$, we equivalently write these moments as $E\left(\left(I_{J-1} \otimes \tau^{h k}\right) u^{h k}\left(\theta^{k}\right)\right)=0$.

The set of covariates $\tau^{h k}$ (for single households $h$ ) consists of region dummies, age, log relative prices, log real total expenditure (defined as the log of total expenditures divided by a Stone price index computed for our six nondurable goods) and its square, and the product of log real total expenditures with the home ownership dummy and with log prices. The number of moments therefore consists of $J-1=5$ distinct demand equations times the number of elements of $\tau^{h k}$, which is 22 , for a total of 110 moments each for $k=f$ and for $k=m$. Let $H^{k}$ denote the set of households that consist of a single member of type $k$, and let $n_{k}$ denote the number of elements of $H^{k}$. Denote the sample moments for GMM estimation by

$$
v^{k}\left(\theta^{k}\right)=\frac{1}{n_{k}} \sum_{h \in H^{k}}\left(I_{J-1} \otimes \tau^{h k}\right) u^{h k}\left(\theta^{k}\right)
$$

the GMM criterion function is then $\widehat{\theta}^{k}=\arg \min _{\theta^{k}} v^{k}\left(\theta^{k}\right)^{\prime} W^{k} v^{k}\left(\theta^{k}\right)$.

Although we do not use it for our main analysis, in addition to estimating the above model for single men and for single women, we for comparison also estimate it for other households (couples with 0-4 children). For multiple member households, this corresponds to what is known in the collective household literature as a unitary model, that is, a model that treats a household as if it was a single maximizing agent. We provide this unitary model just for comparison to singles, and to our later collective model estimates. Illustrating the differences in demands of single women, single men, and other households, Figure 1 in Appendix D of the Supplemental Appendix presents fitted Engel curve plots for our six goods, with total expenditures $y$ ranging from the 1st to the 
99th percentile. We shift the plots for couples with 0-4 children to the left in these figures to make them comparable to the singles plots. We find that food (at home and eating-out), utility, and communication are necessities while clothing and shoes, transportation, and entertainment are luxuries. Single women have a steeper Engel curve slope for clothing and shoes compared to other households. Couples with 0-4 children have a steeper Engel curve slope for entertainment compared to singles. Elasticity estimates for single women and single men are reported in Table 1 in Appendix D of the Supplemental Appendix.

\subsection{The Joint Model}

Unlike singles, who have budget share equations for six goods, couples have budget shares $\omega_{j}^{h}\left(p, s^{h}, y^{h}\right)$ for seven or eight goods, since they include men's clothes, women's clothes, and (when present) children's clothes as separate goods, while singles just consume one type of clothing.

The parameters of the joint model consist of all the QUAIDS parameters of budget shares, $\omega^{h f}$, $\omega^{h m}$, and $\omega^{h c}$, the Barten scales $A_{s}$, and the parameters of the sharing rules $\eta_{s}^{h f}$ and $\eta_{s}^{h m}$. We jointly estimate all the parameters of the model using data from both singles and couples.

We have 150 preference parameters $(5 \times 17-10=75$ symmetry constrained QUAIDS parameters for each of men and women). We also have 6 Barten scale parameters and 16 sharing rule parameters (the 7 listed above plus the constant for each of men and women); this gives a total of 172 parameters. We have 335 instruments (for each of the 5 goods there are 22 instruments for single men, 22 for single women, and 23 for couples), giving a maximum degrees of freedom of 163 for the most general model. The GMM weighting matrices for singles, $W^{f}$ and $W^{m}$, are obtained from the QUAIDS estimates for singles in the previous subsection. The weighting matrix for children, $W^{c}$ is derived using two-step GMM on the full system, starting with an initial identity weighting matrix. The GMM criterion is:

$$
\min _{\theta}\left(v^{c}(\theta)^{\prime} W^{c} v^{c}(\theta)+v^{f}(\theta)^{\prime} W^{f} v^{f}(\theta)+v^{m}(\theta)^{\prime} W^{m} v^{m}(\theta)\right)
$$

where $\theta$ is the full parameter vector of the joint model and the instrument matrices are defined as in equation (19). 
Table 1: Summary Statistics, JHPS/KHPS 2004 - 2016

\begin{tabular}{|c|c|c|c|c|c|c|}
\hline & \multirow{2}{*}{ Single Men } & \multirow{2}{*}{ Single Women } & \multirow[b]{2}{*}{0 child } & \multicolumn{3}{|c|}{ Couples with } \\
\hline & & & & 1 children & 2 children & 3 - 4 children \\
\hline Number of observations & 1,180 & 822 & 375 & 706 & 1,364 & 395 \\
\hline Number of unique households & 357 & 276 & 192 & 282 & 456 & 138 \\
\hline Household income (thousand yen) & 3460.66 & & 7520.87 & 5910.11 & 6408.41 & 6400.97 \\
\hline Total expenditures (January, thousand yen) & 121.20 & 113.33 & 181.33 & 175.14 & 191.00 & 202.10 \\
\hline Budget share (food) & 0.45 & 0.40 & 0.34 & 0.35 & 0.36 & 0.38 \\
\hline Budget share (clothing) & 0.05 & 0.08 & 0.09 & 0.08 & 0.08 & 0.07 \\
\hline Budget share (communication) & 0.11 & 0.11 & 0.12 & 0.13 & 0.12 & 0.13 \\
\hline Budget share (entertainment) & 0.18 & 0.16 & 0.23 & 0.22 & 0.23 & 0.22 \\
\hline Budget share (transportation) & 0.08 & 0.09 & 0.09 & 0.09 & 0.07 & 0.07 \\
\hline Budget share (utility) & 0.13 & 0.15 & 0.13 & 0.14 & 0.14 & 0.14 \\
\hline Husband clothing\&shoes share & - & - & 0.04 & 0.02 & 0.01 & 0.01 \\
\hline Wife clothing\&shoes share & - & - & 0.05 & 0.02 & 0.02 & 0.01 \\
\hline Children clothing\&shoes share & - & - & 0.00 & 0.03 & 0.04 & 0.04 \\
\hline Female age & - & 47.09 & 38.29 & 37.79 & 38.37 & 38.26 \\
\hline Female unemployed & - & 0.11 & 0.10 & 0.23 & 0.22 & 0.22 \\
\hline Female college graduate or above & - & 0.20 & 0.07 & 0.10 & 0.10 & 0.07 \\
\hline Female some college & - & 0.40 & 0.33 & 0.30 & 0.28 & 0.21 \\
\hline Male age & 48.05 & - & 39.20 & 39.12 & 39.89 & 39.29 \\
\hline Male unemployed & 0.07 & - & 0.01 & 0.00 & 0.00 & 0.00 \\
\hline Male college graduate or above & 0.19 & - & 0.07 & 0.10 & 0.07 & 0.10 \\
\hline Male some college & 0.46 & - & 0.39 & 0.27 & 0.26 & 0.30 \\
\hline Child 1 age & - & - & - & 6.80 & 9.72 & 11.41 \\
\hline Child 2 age & - & - & - & - & 6.50 & 8.68 \\
\hline Child 3 age & - & - & - & - & - & 5.34 \\
\hline Child 4 age & - & - & - & - & - & - \\
\hline Child average age & - & - & - & 6.79 & 8.11 & 8.33 \\
\hline Home ownership & 0.36 & 0.41 & 0.49 & 0.59 & 0.73 & 0.80 \\
\hline
\end{tabular}

Notes: Income and expenditures are in thousand yen. JHPS/KHPS covers years 2004 - 2016. Expenditures are for January. Definition of aggregate goods in JHPS/KHPS: food expenditure includes eating out. Transportation includes automobile expenses, fares, commuting passes, taxes, and tolls. Communications includes postage, fixedline, and mobile phone charges. Culture \& amusement includes stationery, sporting goods, travel, hobbies. Utility includes electricity, gas, water (supply \& sewage). Clothing includes both clothese and shoes. All sources of income are before tax in the past year. "." means observations are all missing for this variable. "-" means information not available/not applicable. For education variable, college graduate or above in JHPS/KHPS includes junior college or technical college, univeristy, or graduate school. Household income refers to annual take-home income (after tax and social insurance deductions). 
Table 2: Estimation Results: the Sharing Rule Parameters and Barten Scales

\begin{tabular}{lcccc}
\hline & \multicolumn{2}{c}{ Wife } & \multicolumn{2}{c}{ Husband } \\
Panel A: the Sharing Rule & Coef & Std Error & Coef & Std Error \\
\hline Constant & $-0.701^{* *}$ & 0.378 & $-0.913^{*}$ & 0.671 \\
Difference in log income (female - male) & -0.069 & 0.090 & -0.106 & 0.127 \\
Difference in age (female - male) & -0.003 & 0.013 & 0.017 & 0.018 \\
Number of children & $-0.357^{* * *}$ & 0.096 & -0.101 & 0.263 \\
Minimum child age less 5 & -0.375 & 0.500 & -0.151 & 0.761 \\
Female age less 39 & 0.223 & 0.253 & 0.409 & 0.574 \\
Wife some college & $0.925^{* * *}$ & 0.613 & -0.869 & 1.578 \\
Husband some college & 0.524 & 0.549 & 0.347 & 0.568 \\
& & & & \\
Panel B: Estimates of Barten Scales & Barten scale & Std Error \\
\hline Food & $0.838^{* * *}$ & 0.211 \\
Clothing and shoes & 1.000 & - \\
Communication & $0.845^{* * *}$ & 0.337 \\
Entertainment & $0.665^{* * *}$ & 0.266 \\
Transportation & $0.760^{* * *}$ & 0.270 \\
Utility & $0.562^{*}$ & 0.379 \\
\hline
\end{tabular}

Notes: Barten Scales are assumed to be homogeneous across all households. The Barten scales of clothing and shoes are assumed to be 1 (purely private). ${ }^{*} \mathrm{p}<0.10,{ }^{* *} \mathrm{p}<0.05,{ }^{* * *} \mathrm{p}<0.01$.

Table 3: Estimated Resource Shares by Types of Households

\begin{tabular}{llccccc}
\hline & & 0 child & 1 child & 2 children & $3-4$ children & All households \\
\hline \multirow{2}{*}{ Women } & Mean & 0.51 & 0.30 & 0.24 & 0.17 & 0.28 \\
& Std Dev & 0.12 & 0.11 & 0.10 & 0.07 & 0.14 \\
\hline \multirow{2}{*}{ Chen } & Mean & 0.49 & 0.24 & 0.25 & 0.27 & 0.28 \\
& Std Dev & 0.12 & 0.10 & 0.10 & 0.10 & 0.13 \\
\hline \multirow{2}{*}{ Children } & Mean & - & 0.45 & 0.50 & 0.56 & 0.43 \\
& Std Dev & - & 0.07 & 0.07 & 0.07 & 0.19 \\
\hline
\end{tabular}

Notes: For women, men, and children, the first row reports the mean resource shares of wives across households with zero to three/four children and across all households. "Std Dev" means standard deviation. 


\section{Table 4: Sharing Rule Implications}

\begin{tabular}{lc}
\hline Household Characteristics & Wife's resource share \\
\hline & All households \\
Benchmark & 0.21 \\
Wife with some college education & 0.45 \\
Husband with some college education & 0.32 \\
Home owner & 0.19 \\
\hline
\end{tabular}

Notes: The benchmark households (row 1) are ones in which neither the wife nor the husband has college education and are renters with median total expenditure. Row 2 shows the wife's resource share in households that are similar to the benchmark households but in which the wife has college education. Row 3 shows the wife's resource share in households that are similar to the benchmark households but in which the husband has college education. Row 4 shows the wife's resource share in households that are similar to the benchmark households but are home owners.

Table 5: Implications of Estimates

\begin{tabular}{lcccc}
\hline & \multicolumn{4}{c}{ Couples with } \\
\cline { 2 - 5 } & 0 child & 1 child & 2 children & $3-4$ children \\
\hline Wife's resource share & 0.51 & 0.30 & 0.24 & 0.17 \\
Wife's equivalent expenditure & 121.66 & 69.79 & 59.71 & 45.15 \\
Husband's equivalent expenditure & 119.80 & 56.47 & 62.58 & 69.09 \\
Children's equivalent expenditure & - & 107.47 & 126.26 & 148.15 \\
Actual couple's expenditure & 181.82 & 173.31 & 183.40 & 192.64 \\
Indifference scale for women & 0.67 & 0.40 & 0.32 & 0.23 \\
Indifference scale for men & 0.66 & 0.33 & 0.34 & 0.36 \\
Indifference scale for children & - & 0.62 & 0.69 & 0.77 \\
Scale economy, R & 0.33 & 0.35 & 0.35 & 0.36 \\
Number of Observations & 379 & 704 & 1369 & 392 \\
\hline
\end{tabular}

Notes: Values are in mean. Equivalent budget share is the budget share of the wife (husband) if she (he) is endowed with the fraction of resources and faced with shadow prices (market prices discounted by the Barten scales). The equivalent expenditure is the expenditure that the wife (husband) needs to obtain the same private good equivalents in marraige if she (he) is living alone, endowed with the fraction of resources in marriage and faced with market prices. Scale economy means it would cost the couple $\mathrm{R}$ percent more to buy the (private equivalent) goods they consumed if there had been no shared or joint consumption. The expenditures are in thousand yen. 


\subsection{Resource Shares and Barten Scales}

The main results for our preferred model are displayed in Table 2. Panel A in Table 2 reports estimates of the sharing rule parameters. The estimated resource shares for each type of household member (wives, husbands, and children) are reported in Table 3. The mean value of the wife's resource share is 0.51 in couples without children, 0.3 in couples with 1 child, 0.24 in couples with 2 children, and 0.17 in couples with 3 or 4 children. The mean value of the husband's resource share is 0.49 in couples without children, 0.24 in couples with 1 child, and stays almost constant as the number of children increases to 3 or 4 . These results suggest that when there are no children present in the household, wives and husbands have similar resource shares or bargaining power. However, when the number of children rises, mothers on average devote much more of their own resource shares to children compared to fathers. Dunbar et al. (2013) similarly found that the number of children affects husbands' resource shares far less than wives'.

Table 4 reports wives' resource shares conditional on household characteristics. The benchmark household is one in which neither the wife nor the husband has college education and are renters with median total expenditure. The first row shows that at our benchmark values, the wives' resource share is 0.21 .

Rows 2 and 3 show that education has a large impact on wives' resource share. On average, the resource share of wives who have some college education are $92.5 \%$ higher than those who do not. ${ }^{11}$ Even in families where husbands have some college education, wives enjoy a $52.4 \%$ higher resource share than in families where wives do not have any college education.

Wives in households who are home owners have slightly lower resource share. Note that homeowner households also tend to have children, and wives' resource share is lower in families with children.

The large ranges we find in husbands and wives resource shares are surprising, but others have reported similar results in Japanese data. For example, Lise and Yamada (2018) find husband's private consumption is more than double that of wives, and, by a different measure, Fujii and Lin (2018) report husband's consumption is 50\% larger. Both of these studies use a different data set from ours, the Japanese Panel Survey of Consumers (JPSC). The JPSC reports private consumption of husbands and wives, but, unlike our analysis, does not allocate joint consumption

\footnotetext{
${ }^{11}$ Note that wives with college have $92.5 \%$ higher shares only on average. For example, due to model nonlinearity, while all women without children have a 0.51 share on average, the share for college educated women without children is 0.63 , which is much less than a $92.5 \%$ increase from 0.51 . Childless women without college have an average share of 0.45 .
} 
(which constitutes over three fourths of all household consumption in the JPSC).

As another check on our estimates, we do our own comparison (in Appendix C of the Supplemental Appendix) to self-reports of individual private consumption in the JPSC. Overall, our estimates are comparable to the JPSC reports, however, by failing to allocate shared goods, we find that the JPSC appears to underestimate the relative contribution of wives vs. husbands to children's resources.

Estimates of Barten scales are reported in Panel B of Table 2. Clothing and shoes are our private assignable goods, so their Barten scales equal one. We find that food and communication are highly private (having Barten scales close to one), while communication and utility are highly public (i.e., they have Barten scales well below one, indicating that they are largely jointly consumed among household members). Transportation, which includes both private cars and public transportation, is found to be somewhat jointly consumed among household members. These Barten scales are generally consistent with findings from the previous literature, including BCL, Cherchye et al. (2012), Solvejg (2016), Lin (2018), and Fujii and Lin (2018).

A difference between our nonparametric identification theory and our parametric empirical implementation is that we include income as a distribution factor, while the theory assumed the elements of $s$ are all discrete. As a robustness check, we divide household income into ten brackets and re-estimate the model. The results are reported in Table 2 in Appendix D of the Supplemental Appendix. This discretization sacrifices some information, but the signs and magnitude on our sharing rule parameters and Barten scales remain similar to our baseline model estimates.

\subsection{Indifference Scales and Economies of Scale}

We next consider household member's private equivalent expenditures, and the resulting household's economies of scale to consumption. The private good equivalent of good $j$ by member $k$ in household $h, x_{j}^{h k}$, is the quantity of good $j$ that member $k$ consumes, accounting for the extent to which that good is shared with other members. The more public a good is, and hence the more that good is

shared, the lower is its Barten scale, and the greater is the sum of $x_{j}^{h k}$ across household members $k$, relative to $z_{j}^{h}$, the household's purchased quantity of good $j$.

A household's economies of scale to consumption is how much more it would cost to buy every member's private good equivalents at market prices, relative to the household's actual total expenditure level. Given our estimates of budget shares for singles, resource shares, and Barten scales, 
the private good equivalent quantities for each household member $k$ for each good $j$ are given by

$$
x_{j}^{h k}=\frac{\omega_{j}^{h k}}{a_{s j}} \eta_{s}^{h k} y^{h}
$$

and relative economies of scale to consumption $R$ are defined as

$$
R=\frac{\sum_{j} p_{j} \sum_{k} x_{j}^{h k}}{y^{h}}-1=\frac{\left.\sum_{j} p_{j}\left(\left(\sum_{k} x_{j}^{h k}\right)-z_{j}^{h}\right)\right)}{\sum_{j} p_{j} z_{j}^{h}} .
$$

BCL define a member's indifference scale to be the cost (as a fraction of $y$ ), at market prices, of the cheapest bundle of goods that gets member $k$ to the same utility level (i.e., the same indifference curve over goods) that the member attains in the household by consuming his or her own vector of private good equivalents. Let $\widetilde{V}^{k}$ denote the QUAIDS indirect utility function of member $k$. The indifference scale $I S^{h k}$ for each member $k$ is defined as the solution to

$$
\widetilde{V}^{k}\left(\frac{p / y}{I S^{h k}}\right)=\widetilde{V}^{k}\left(\frac{A_{s} p / y}{\eta_{s}^{h k}}\right)
$$

Table 5 reports the estimates of members' private good equivalent expenditures $x^{k}$, indifference scales $I S^{k}$, and the overall economies of scale $R$. Row 6 in Table 5 reports the indifference scale for wives. This indifference scale can be interpreted as the fraction of the household's total expenditures that a wife would need when living alone (i.e., as a single) to attain the same indifference curve over goods that she reaches as a member of the household. The table shows that, on average, wives would require $67 \%$ of the couple's total expenditures to be as well off living alone as she is in the couple, when there are no children. This drops to only $23 \%$ in families with 3 to 4 children, reflecting how much less, relatively, women consume when children are present. The corresponding numbers for husbands (in row 7 of Table 5) are $66 \%$ without children, dropping to $36 \%$ when 3 to 4 children are present.

The interpretation of an indifference scale as the relative cost of living alone is not relevant for children, however, indifference scales for children still provide a measure of the savings in costs of children that households attain by sharing consumption, and it is meaningful to compare the relative values of children's indifference scales in households of different compositions. Children's indifference scales are reported in row 8 of Table 5. 
The second to the last row in Table 5 gives household's overall economies of scale. On average, it ranges between 0.33 to 0.36 across different household types. This implies that it would cost families $33 \%$ to $36 \%$ more to buy the (private equivalent) goods they consumed if there had been no shared or joint consumption.

\section{Conclusions}

We provide theorems for point identifying a general class of semiparametric models that are applicable to a variety of applications, including continuous consumer demand, production functions, and multiple index models. We then extend these results to show point identification for a large class of collective household models, which previously had only been shown to be generically identified. Moreover, we do so in a model that allows goods to be partly shared, including identifying the demand functions and resource shares of children.

We apply our model to Japanese data consisting of single men, single women, and married couples with zero to four children. Our findings have important policy implications for the analysis of individual welfare, particularly children's welfare, in multi-person households. For example, one potential application of our identification and resulting estimates could be to calculate appropriate levels of compensation for children, to maintain their standard of living, if parents separate or a parent dies. Also, since we identify (ordinally) the utility functions of children and their parents, the framework can be used to evaluate the impact of welfare programs (e.g., taxes or subsidies) on the individual welfare of mothers, fathers, and children.

\section{References}

Ackerberg, D.A., K. Caves, and G. Frazer (2015), Identification Properties of Recent Production Function Estimators. Econometrica, 83, 2411-2451

Ahn, H., H. Ichimura, J. L. Powell, and P. A. Ruud (2018) Simple Estimators for Invertible Index Models, Journal of Business \& Economic Statistics, 36(1), 1-10.

Ai, C. and Chen, X. (2003), Efficient Estimation of Models with Conditional Moment Restrictions Containing Unknown Functions. Econometrica, 71: 1795-1843.

Banks, J., Blundell, R., and Lewbel, A. (1997). Quadratic Engel curves and consumer demand. The review of economics and statistics, 79(4), 527-539. 
Bargain, O., and Donni, O. (2012). Expenditure on children: A Rothbarth-type method consistent with scale economies and parents' bargaining. European Economic Review, 56(4), 792-813.

Barten, A. P. (1964), "Family Composition, Prices, and Expenditure Patterns," in Hart, P., Mills, G. and Whitaker, J. K.(eds) Econometric Analysis for National Economic Planning: 16th Symposium Colston Society (London: Butterworth), 277-292.

Basu, S. and J. G. Fernald, 1997, Returns to Scale in U.S. Production: Estimates and Implications Journal of Political Economy 105(2), 249-283.

Becker, G. (1965), "A Theory of the Allocation of Time", Economic Journal, 75, 493-517.

Becker, G. S., (1981) A Treatise on the Family. Cambridge, MA: Harvard University Press.

Bonke, J. and M. Browning, (2011), "Spending on Children: Direct Survey Evidence," The Economic Journal, 121(554), F123-F143.

Browning, M., Bourguignon, F., Chiappori, P. A., and Lechene, V. (1994). Income and outcomes: A structural model of intrahousehold allocation. Journal of political Economy, 102(6), 1067-1096.

Browning, M., and Chiappori, P. A. (1998). Efficient intra-household allocations: A general characterization and empirical tests. Econometrica, 1241-1278.

Browning, M., Chiappori, P. A., and Lewbel, A. (2013). Estimating consumption economies of scale, adult equivalence scales, and household bargaining power. Review of Economic Studies, 80(4), 1267-1303.

Blundell, R., Chiappori, P. A., and Meghir, C. (2005). Collective labor supply with children. Journal of political Economy, 113(6), 1277-1306.

Calvi, R. (2020). "Why Are Older Women Missing in India? The Age Profile of Bargaining Power and Poverty," forthcoming, Journal of Political Economy.

Calvi, R., Lewbel, A., and Tommasi, D. (2019). Women's Empowerment and Family Health: Estimating LATE with Mismeasured Treatment. Available at SSRN 2980250.

Chamberlain, G. (1986). Asymptotic efficiency in semi-parametric models with censoring. journal of Econometrics, 32(2), 189-218.

Cherchye, L., De Rock, B., and Vermeulen, F. (2012a). Married with children: A collective labor supply model with detailed time use and intrahousehold expenditure information. The American Economic Review, 102(7), 3377-3405.

Cherchye, L., De Rock, B., and Vermeulen, F. (2012b). Economic well-being and poverty among the elderly: an analysis based on a collective consumption model. European Economic Review, 56(6), 985-1000. 
Cherchye, L., De Rock, B., Lewbel, A., and Vermeulen, F. (2015). Sharing rule identification for general collective consumption models. Econometrica, 83(5), 2001-2041.

Cherchye, L., Demuynck, T., De Rock, B., and Vermeulen, F. (2017). Household consumption when the marriage is stable. American Economic Review, 107(6), 1507-1534.

Chiappori, P. A. (1988). Rational household labor supply. Econometrica: Journal of the Econometric Society, 63-90.

Chiappori, P. A. (1992). Collective labor supply and welfare. Journal of political Economy, 100(3), 437-467.

Chiappori, P. A., and Ekeland, I. (2006). The micro economics of group behavior: general characterization. Journal of Economic Theory, 130(1), 1-26.

Chiappori, P. A., and Ekeland, I. (2009). The Microeconomics of Efficient Group Behavior: Identification 1. Econometrica, 77(3), 763-799.

Chiappori, P. A., Fortin, B., and Lacroix, G. (2002). Marriage market, divorce legislation, and household labor supply. Journal of political Economy, 110(1), 37-72.

Couprie, H., Peluso, E., and Trannoy, A. (2010). Is power more evenly balanced in poor households? Journal of Public Economics, 94(7-8), 493-507.

Donkers, B., and M. Schafgans, (2008). Specification and estimation of semiparametric multipleindex models. Econometric Theory, 24(6), 1584-1606.

Dunbar, G. R., Lewbel, A., and Pendakur, K. (2013). Children's resources in collective households: identification, estimation, and an application to child poverty in Malawi. American Economic Review, 103(1), 438-71.

Folkertsma, C. (1995) "Estimation of Household Equivalence Scales in a Model with Joint Determination of Commodity Demand and Labour Supply," Journal of Income Distribution, 4(2), 235-252.

Fujii, T., and Lin, X. (2018). Individual Welfare Analysis in Japanese Couples without Children. Boston College Working Papers.

Gandhi, A., S. Navarro, and D. A. Rivers (2020) "On the Identification of Gross Output Production Functions," Journal of Political Economy, forthcoming.

Gorman, W.M. (1981) "Some Engel Curves," in Deaton, A., Ed., Essays in the Theory and Measurement of Consumer Behaviour: In Honour of Sir Richard Stone, Cambridge University Press, Cambridge, 7-30.

Heckman, J. (1990). Varieties of selection bias. The American Economic Review, 80(2), 313. 
Horowitz, J. (1998) Semiparametric Methods in Econometrics, NewYork:Springer

Ichimura, H., and Lee, L. F. (1991), "Semiparametric Least Squares Estimation of Multiple Index Models: Single Equation Estimation," in Nonparametric and Semiparametric Methods in Econometrics and Statistics: Proceedings ofthe Fifth International Symposium in Economic Theory and Econometrics,eds. W. A. Barnett, J. Powell, and G. Tauchen, Cambridge, U.K.: Cambridge University Press

Jorgenson, D., L.J. Lau, and T.M. Stoker (1982) "The Transcendental Logarithmic Model of Aggregate Consumer Behavior." In Advances in Econometrics , edited by RL Basmann and G Rhodes, 97-238. Greenwich: JAI Press.

Khan, S. and Tamer, E. (2010), "Irregular Identification, Support Conditions, and Inverse Weight Estimation," Econometrica, 78, 2021-2042.

Lewbel, A. (1991), "The Rank of Demand Systems: Theory and Nonparametric Estimation," Econometrica, 59(3) 711-730.

Lewbel, A. (1998), "Semiparametric latent variable model estimation with endogenous or mismeasured regressors," Econometrica, 66, 105-121.

Lewbel A. (2001), "Demand Systems with and without Errors." American Economic Review, 91(3), 611-618.

Lewbel, A. (2019), "The Identification Zoo: Meanings of Identification in Econometrics," Journal of Economic Literature, 57(4), 835-903.

Lewbel, A., and Pendakur, K. (2008) Estimation of collective household models with Engel curves, Journal of Econometrics, 147(2),350-358.

Lewbel, A., and Pendakur, K. (2017). Unobserved preference heterogeneity in demand using generalized random coefficients. Journal of Political Economy, 125(4), 1100-1148.

Lewbel, A., and Pendakur, K. (2019). Inefficient Collective Households: Abuse and Consumption. Boston College unpublished manuscript

Lin, X., (2018). SNAP and Food Consumption among Older Adults: A Collective Household Approach with Homescan Data. Boston College Working Papers.

Lindahl, E. (1958). Just taxation - a positive solution. In Classics in the theory of public finance (pp. 168-176). Palgrave Macmillan, London.

Lise, J., and Seitz, S. (2011). Consumption inequality and intra-household allocations. The Review of Economic Studies, 78(1), 328-355.

Lise, J., and Yamada, K. (2014). Household sharing and commitment: Evidence from panel data 
on individual expenditures and time use (No. W14/05). IFS Working Papers.

Matzkin, R. L. (2003). Nonparametric estimation of nonadditive random functions. Econometrica, 71(5), 1339-1375.

Matzkin, R. L. (2007). Nonparametric identification. Handbook of econometrics, 6, 5307-5368.

Matzkin, R. L. (2012). Identification in nonparametric limited dependent variable models with simultaneity and unobserved heterogeneity. Journal of Econometrics, 166(1), 106-115.

McManus, D. A. (1992), "How common is identification in parametric models?" Journal of Econometrics, 53(1), 5-23.

Menon, M., Pendakur, K., and Perali, F. (2012). On the expenditure-dependence of children's resource shares. Economics Letters, 117(3), 739-742.

Penglase, J. (2019), "Consumption Inequality Among Children:Evidence from Child Fostering in Malawi," Unpublished manuscript, Boston College.

Pollak, R., and Wales, T. (1981). Demographic Variables in Demand Analysis. Econometrica, $49(6), 1533-1551$.

Prais, Sigbert J., and Hendrik S. Houtakker, 1955, The analysis of household budgets,Cambridge. Cambridge University Press.

Ray R. (2018) Specification and Estimation of Demographic Demand Systems, Equivalence Scales with Selective Empirical Evidence. In: Household Behaviour, Prices, and Welfare. Themes in Economics (Theory, Empirics, and Policy). Springer, Singapore

Vermeulen, F. (2002). Collective household models: principles and main results. Journal of Economic Surveys, 16(4), 533-564.

Wewel, S. (2017). Heterogeneity in Consumption Gains from Living Together as a Couple. Boston College Working Papers.

Xia, Y. (2008) A Multiple-Index Model and Dimension Reduction, Journal of the American Statistical Association, 103:484, 1631-1640,

Xia, Y., Tong, H., Li, W.K., and Zhu, L. (2002). An adaptive estimation of dimension reduction space (with discussion). Journal of the Royal Statistical Society Series B, 64, 363-410. 


\section{A Appendix}

\section{A.1 Appendix A: Proofs}

PROOF of LEMMA 1: The function $G(p)$ is identified for all $p \in \Omega_{p}$ by $G(p)=M(p, t)$, where $t$ is defined in Assumption A2. Also, the functions $m_{j}(p, s)$ and $g_{j}(p)$ are identified (where the derivatives defining these functions exist) for all $p \in \Omega_{p}$ by construction because they are derivatives of identified functions.

Now let Assumption A3 hold. Since $m_{j}(p, s)=g_{j}\left(a_{s 1} p_{1}, \ldots a_{s J} p_{J}\right)$, we have that

$$
\zeta_{j}(\alpha, \widetilde{p}, s)=a_{s j} \frac{g_{j}\left(a_{s 1} \widetilde{p}_{1}, \ldots a_{s J} \widetilde{p}_{J}\right)}{g_{j}\left(\alpha_{1} \widetilde{p}_{1}, \ldots \alpha_{J} \widetilde{p}_{J}\right)} \text { for } j=1, \ldots, J
$$

Since this mapping is a contraction, by the Banach fixed point theorem there exists is a unique $\alpha$ such that $\alpha=\zeta(\alpha, \widetilde{p}, s)$. This unique $\alpha$ is identified, because the value of the function $\zeta(\alpha, \widetilde{p}, s)$ is identified. But by equation (24), $a_{s}=\zeta\left(a_{s}, \widetilde{p}, s\right)$, and therefore the unique identified $\alpha$ is the desired coefficient vector $a_{s}$.

Next, suppose instead that Assumption A4 holds. For all $p$ in the neighborhood of zero given by Assumption A2, let $m_{j}(p, s)=\partial M(p, s) / \partial p_{j}$ and let $g_{j}(p)=\partial G(p) / \partial p_{j}$ (these can be one

sided derivatives). These functions are identified by construction given that $M(p, s)$ and $G(p)$ are identified. Then, it follows from equation (24) that $a_{s}$ is identified by $a_{s j}=\zeta_{j}(0,0, s)=$ $\lim _{p \rightarrow 0} m(p, s) / g_{j}(p)$ (where, e.g., this limit is from above if $p>0$ ).

Finally, given identification of each $a_{s}$, the function $G(z)$ is identified not just for all $z \in \Omega_{p}$ but for all $z \in \Omega_{z}$ by $G\left(a_{s 1} p_{1}, \ldots a_{s J} p_{J}\right)=M(p, s)$ for all $(p, s) \in \Omega_{p} \times \Omega_{s}$.

\section{PROOF of LEMMA 2:}

First observe that, given $\Omega_{p}$ is the positive orthant and all $a_{s j}$ are positive, it follows that $\Omega_{z}$ is also the positive orthant, and therefore that $G(z)$ is identified for all $z \in \Omega_{z}$, by $G(p)=M(p, 0)$. It follows that $c_{j}$ defined by equation (4) is also identified, since $G(p)$ is identified over the positive orthant and the function $\psi_{j}$ is chosen. Next define constants $C_{s j}$ by

$$
C_{s j}=\int_{0}^{\infty} \ldots \int_{0}^{\infty} \psi_{j}[M(p, s)] p_{1}^{-1} \ldots p_{j-1}^{-1} p_{j+1}^{-1} \ldots p_{J}^{-1} d p_{1} \ldots d p_{J}
$$

Each $C_{s j}$ is identified, since $M(p, s)$ is identified for all $p$ over the positive orthant and all $s \in \Omega_{s}$, and the function $\psi_{j}$ is chosen. Notice that $c_{j}=C_{0 j}$. Then, using the change of variables $\phi_{j}=a_{s j} p_{j}$ 
for each good $j$,

$$
\begin{aligned}
C_{s j} & =\int_{0}^{\infty} \ldots \int_{0}^{\infty} \psi_{j}\left[G\left(a_{s 1} p_{1}, \ldots a_{s J} p_{J}\right)\right] p_{1}^{-1} \ldots p_{j-1}^{-1} p_{j+1}^{-1} \ldots p_{J}^{-1} d p_{1} \ldots d p_{J} \\
& =\int_{0}^{\infty} \ldots \int_{0}^{\infty} \psi\left[G\left(\phi_{1}, \ldots \phi_{J}\right)\right] \frac{a_{s 1}}{\phi_{1}} \ldots \frac{a_{s, j-1}}{\phi_{j-1}} \frac{a_{s, j+1}}{\phi_{j+1}} \ldots \frac{a_{s J}}{\phi_{J}} \frac{d \phi_{1}}{a_{s 1}} \ldots \frac{d \phi_{J}}{a_{s J}} \\
& =\int_{0}^{\infty} \ldots \int_{0}^{\infty} \psi\left[G\left(\phi_{1}, \ldots \phi_{J}\right)\right] \frac{1}{\phi_{1}} \ldots \frac{1}{\phi_{j-1}} \frac{1}{\phi_{j+1}} \ldots \frac{1}{\phi_{J}} d \phi_{1} \ldots d \phi_{J} \frac{1}{a_{s j}}=\frac{c_{j}}{a_{s j}}
\end{aligned}
$$

so $a_{s j}$ is identified for each $s \in \Omega_{s}$ and $j \in\{1, \ldots, J\}$ by $a_{s j}=c_{j} / C_{s j}$.

PROOF of THEOREM 1: This follows immediately from Lemmas 1 and 2, noting that without the normalization of Assumption A2, the coefficients $a_{s j}$ in the proofs of Lemmas 1 and 2 correspond to $a_{s j} / a_{t j}$ for some $t \in \Omega_{s}$ where the function $G(p)$ in these proofs corresponds to $G\left(a_{t 1} p_{1}, \ldots a_{t J} p_{J}\right)$

PROOF of THEOREM 2: If Assumption B2 holds then without loss of generality let $j=k$. Let $h_{j}^{j \prime}(p, y)=\partial h_{j}^{j}(p, y) / \partial y$. Then

$$
\begin{aligned}
M(p, s) & =\lim _{y \rightarrow 0} \frac{\partial\left[\eta_{s}^{j}\left(A_{s} p\right) h_{j}^{j}\left(A_{s} p, \eta_{s}^{j}\left(A_{s} p\right) y\right)\right] / \partial y}{\eta_{s}^{j}\left(A_{s} p\right)^{2} h_{j}^{j}\left(A_{s} p, \eta_{s}^{j}\left(A_{s} p\right) y\right)^{2}} \\
& =\lim _{y \rightarrow 0} \frac{\eta_{s}^{j}\left(A_{s} p\right) \partial\left[\eta_{s}^{j}\left(A_{s} p\right) h_{j}^{j}\left(A_{s} p, \eta_{s}^{j}\left(A_{s} p\right) y\right)\right] / \partial\left[\eta_{s}^{j}\left(A_{s} p\right) y\right]}{\eta_{s}^{j}\left(A_{s} p\right)^{2} h_{j}^{j}\left(A_{s} p, \eta_{s}^{j}\left(A_{s} p\right) y\right)^{2}} \\
& =\lim _{y \rightarrow 0} \frac{h_{j}^{j \prime}\left(A_{s} p, \eta_{s}^{j}\left(A_{s} p\right) y\right)}{h_{j}^{j}\left(A_{s} p, \eta_{s}^{j}\left(A_{s} p\right) y\right)^{2}} \\
& =\lim _{y \rightarrow 0} \frac{h_{j}^{j \prime}\left(A_{s} p, y\right)}{h_{j}^{j}\left(A_{s} p, y\right)^{2}}=G\left(A_{s} p\right)
\end{aligned}
$$

where the last equality above defines the function $G$.

Alternatively, if Assumption B3 holds then the same steps as above applied separately to good $j$ and to good $j^{\prime}$ yield

$$
M(p, s)=\lim _{y \rightarrow 0} \frac{h_{j}^{j \prime}\left(A_{s} p, y\right)}{h_{j}^{j}\left(A_{s} p, y\right)^{2}} / \frac{h_{\widetilde{j}}^{\widetilde{j}}\left(A_{s} p, y\right)}{h_{\tilde{j}}^{\tilde{j}}\left(A_{s} p, y\right)^{2}}=G\left(A_{s} p\right)
$$

Next, consider the case where Assumption B4 holds. Then again without loss of generality let 
$j=k$ and we have

$$
M(p, s)=\int_{0}^{\infty}\left[\eta_{s}^{k}\left(A_{s} p\right)\right]^{c}\left[h_{k}^{k}\left(A_{s} p, \eta_{s}^{k}\left(A_{s} p\right) y\right)\right]^{c} y^{c-1} d y
$$

Now do the change of variables $\tau=\eta_{s}^{k}\left(A_{s} p\right) y$

$$
\begin{aligned}
M(p, s) & =\int_{0}^{\infty}\left[\eta_{s}^{k}\left(A_{s} p\right)\right]^{c}\left[h_{k}^{k}\left(A_{s} p, \tau\right)\right]^{c}\left[\frac{\tau}{\eta_{s}^{k}\left(A_{s} p\right)}\right]^{c-1} \frac{d \tau}{\eta_{s}^{k}\left(A_{s} p\right)} \\
& =\int_{0}^{\infty}\left[h_{k}^{k}\left(A_{s} p, \tau\right)\right]^{c} \tau^{c} d \tau=G\left(A_{s} p\right)
\end{aligned}
$$

where the last equality above defines the function $G$.

Now, if Assumption B5 holds then

$$
\begin{aligned}
M(p, s) & =\int_{0}^{\infty}\left(\sum_{k=1}^{K} \eta_{s}^{k}\left(A_{s} p\right) h_{j}^{k}\left(A_{s} p, \eta_{s}^{k}\left(A_{s} p\right) y\right)\right) d y \\
& =\sum_{k=1}^{K} \int_{0}^{\infty} \eta_{s}^{k}\left(A_{s} p\right) h_{j}^{k}\left(A_{s} p, \eta_{s}^{k}\left(A_{s} p\right) y\right) d y
\end{aligned}
$$

Next do the change of variables $\tau=\eta_{s}^{k}\left(A_{s} p\right) y$ in each of the $K$ integrals above.

$$
\begin{aligned}
M(p, s) & =\sum_{k=1}^{K} \int_{0}^{\infty} \eta_{s}^{k}\left(A_{s} p\right) h_{j}^{k}\left(A_{s} p, \tau\right) \frac{d \tau}{\eta_{s}^{k}\left(A_{s} p\right)} \\
& =\sum_{k=1}^{K} \int_{0}^{\infty} h_{j}^{k}\left(A_{s} p, \tau\right) d \tau=G\left(A_{s} p\right)
\end{aligned}
$$

where the last equality above defines the function $G$.

Finally, consider the case where B6 holds. If $h_{j}^{k}(p, y)=\sum_{\ell=0}^{L} \psi_{j \ell}^{k}(p)(\ln y)^{\ell}$ for the private assignable $k=j$, then

$$
\omega_{j}(p, s, y)=\eta_{s}^{j}\left(A_{s} p\right) \sum_{\ell=0}^{L} \psi_{j \ell}^{k}\left(A_{s} p\right)\left(\ln y+\ln \eta_{s}^{k}\left(A_{s} p\right)\right)^{\ell}
$$

Therefore $\xi(p, s)=\left(\eta_{s}^{j}\left(A_{s} p\right)\left|\psi_{j L}^{k}\left(A_{s} p\right)\right|\right)^{-1}$ (using the fact that resource shares are positive), so with $M(p, s)=\xi(p, s) \omega_{j}(p, s, \xi(p, s))$ we get

$$
M(p, s)=\frac{\sum_{\ell=0}^{L} \psi_{j \ell}^{k}\left(A_{s} p\right)\left(-\ln \left|\psi_{j L}^{k}\left(A_{s} p\right)\right|\right)^{\ell}}{\left|\psi_{j L}^{k}\left(A_{s} p\right)\right|}
$$


which is a function of just terms of the form $\psi_{j \ell}^{k}\left(A_{s} p\right)$, and so defines $G$.

\section{PROOF of THEOREM 3:}

By Corollary 1, the relative Barten technology parameters $a_{s j} / a_{t j}$ and $a_{r j} / a_{t j}$ are identified for given $r, s$, and $t$ elements of $\Omega_{s}$. Let $A_{s t}$ be the diagonal matrix that has elements $a_{s j} / a_{t j}$ on the

diagonal. Given Assumption $\mathrm{C} 1$, define the identified function $m$ by $\eta_{s}^{k}\left(A_{s t} p\right) h_{k}^{k}\left(A_{s t} p, \eta_{s}^{k}\left(A_{s t} p\right) y\right)$

$$
m(p, s)=\omega_{j}\left(s, \phi_{s t}(p), 0\right)=\eta_{s}^{k}\left(A_{t} p\right) h_{j}^{k}\left(A_{t} p, \eta_{s}^{k}\left(A_{t} p\right) 0\right)
$$

It then follows that relative values of resource shares are identified by

$$
\frac{m(p, s)}{m(p, r)}=\frac{\eta_{s}^{k}\left(A_{t} p\right) h_{j}^{k}\left(A_{t} p, 0\right)}{\eta_{r}^{k}\left(A_{t} p\right) h_{j}^{k}\left(A_{t} p, 0\right)}=\frac{\eta_{s}^{k}\left(A_{t} p\right)}{\eta_{r}^{k}\left(A_{t} p\right)}
$$

Alternatively, given Assumption C2,

$$
m(p, s)=\int_{0}^{\infty}\left[\eta_{s}^{k}\left(A_{t} p\right)\right]^{c_{1}}\left[h_{j}^{k}\left(A_{t} p, \eta_{s}^{k}\left(A_{t} p\right) y\right)\right]^{c_{1}} y^{c_{2}} d y
$$

Now do the change of variables $\tau=\eta_{s}^{k}\left(A_{t} p\right) y$

$$
\begin{aligned}
m(p, s) & =\int_{0}^{\infty}\left[\eta_{s}^{k}\left(A_{t} p\right)\right]^{c_{1}}\left[h_{j}^{k}\left(A_{t} p, \tau\right)\right]^{c_{1}}\left[\frac{\tau}{\eta_{s}^{k}\left(A_{t} p\right)}\right]^{c_{2}} \frac{d \tau}{\eta_{s}^{k}\left(A_{t} p\right)} \\
& =\left[\eta_{s}^{k}\left(A_{t} p\right)\right]^{c_{1}-c_{2}-1} \int_{0}^{\infty}\left[h_{j}^{k}\left(A_{t} p, \tau\right)\right]^{c_{1}} \tau^{c_{2}} d \tau
\end{aligned}
$$

and it then follows that relative values of resource shares are identified by

$$
\left[\frac{m(p, s)}{m(p, r)}\right]^{1 /\left(c_{1}-c_{2}-1\right)}=\frac{\left[\left[\eta_{s}^{k}\left(A_{t} p\right)\right]^{c_{1}-c_{2}-1} \int_{0}^{\infty}\left[h_{j}^{k}\left(A_{t} p, \tau\right)\right]^{c_{1}} \tau^{c_{2}} d \tau\right]^{1 /\left(c_{1}-c_{2}-1\right)}}{\left[\left[\eta_{r}^{k}\left(A_{t} p\right)\right]^{c_{1}-c_{2}-1} \int_{0}^{\infty}\left[h_{j}^{k}\left(A_{t} p, \tau\right)\right]^{c_{1}} \tau^{c_{2}} d \tau\right]^{1 /\left(c_{1}-c_{2}-1\right)}}=\frac{\eta_{s}^{k}\left(A_{t} p\right)}{\eta_{r}^{k}\left(A_{t} p\right)}
$$

\section{PROOF of THEOREM 4:}

Let household. type $t \in \Omega_{s}$ refer to a single. Since singles have no one to share with, they must have all $a_{t j}=1$ for every good $j$. We can therefore apply Corollary 1 and Theorem 2 to identify each $a_{s j} / a_{t j}$ using demand functions $h_{k}^{k}(p, y)$, and since each $a_{t j}=1$ (so $A_{t}$ is the identify matrix) we have identified each $a_{s j}$ for all household types $s$. If Assumption C1 or C2 hold, then 
we also identify all relative resource shares $\eta_{s}^{k}\left(A_{r} p\right) / \eta_{t}^{k}\left(A_{r} p\right)$ by Theorem 3. For singles of type $k=1, \ldots, K-1$, resource shares $\eta_{t}^{k}$ must equal one, so taking $r=t$ we identify $\eta_{s}^{k}(p) / \eta_{t}^{k}(p)=\eta_{s}^{k}(p)$. Alternatively, if Assumption B6 holds, then $h_{j}^{k}(p, y)=\sum_{\ell=0}^{L} \psi_{j \ell}^{k}(p)(\ln (y))^{\ell}$, so the $\psi_{k \ell}^{k}$ functions are known. This, along with all $a_{s j}$ being known for $k=1, \ldots, K-1$ means that resource shares $\eta_{s}^{k}$ can be recovered from equation (8).

Finally resource shares sum to one, so given the resource share functions $\eta_{s}^{k}$ for all household types $s$ and members $k=1, \ldots, K-1$, we identify the resource share functions for the last household type $K$ by $\eta_{s}^{K}(p)=1-\sum_{k=1}^{K-1} \eta_{s}^{k}(p)$. 


\title{
Identification of Semiparametric Model Coefficients, With an Application to Collective Households - SUPPLEMENTAL APPENDIX
}

\author{
Arthur Lewbel* and Xirong Lin \\ Boston College
}

June 21, 2020

This supplement contains Appendices B: Price Data, C: External Validation of Model Predictions, and D: Additional Tables and Figures.

\subsection{APPENDIX B: Price Data}

We use price data from the 2015 based Consumer Price Index (CPI) available from e-Stat, the Portal Site of Official Statistics of Japan. The goal is to construct a price index for each aggregate good for each household in our sample. It is challenging to merge this CPI data into the JHPS/KHPS because the two datasets divide the country somewhat differently. JHPS/KHPS provides the region and city size of the residence of each household. The CPI divides Japan into 10 regions, whereas the JHPS/KHPS divides it into 8 regions. We first reduce the number of regions in the CPI by merging some of the CPI regions to match the definitions in JHPS/KHPS. While most prefectures belong to the same region between the CPI and JHPS/KHPS data after merging, the three prefectures of Yamanashi, Nagano, and Mie are classified to different regions between the CPI and JHPS/KHPS data. $^{1}$

\footnotetext{
*Corresponding Author: Arthur Lewbel, Department of Economics - Maloney 315, Boston College, 140 Commonwealth Ave., Chestnut Hill, MA, 02467, USA. (617)-552-3678, lewbel@bc.edu, https://sites.google.com/bc.edu/arthur-lewbel/

${ }^{1}$ To match the JHPS/KHPS definition of Kyushu region (Fukuoka, Saga, Negasaki, Miyazaki, Kagoshima, Kumamoto, Oita, and Okinawa prefectures), we merged Kyushu and Okinawa regions in CPI. To match the
} 
In addition to regional prices, the CPI dataset provides price data for each "designated city," that is, each major city with a population of more than half million that is designated as such by order of the Cabinet of Japan. ${ }^{2}$ Combining these city level prices using CPI weights, we construct price indices for designated cities within each of the eight regions, except for the Shikoku region where there is no designated city. Using each regional price index and the price indices for designated cities, we additionally back out price indices for the areas outside each designated city in each region. Thus, for each aggregate good, we obtain price data for 15 (8 regions $\times 2$ (designated city or not) -1 (no designated city in Shikoku region)) combinations of regions and city sizes, which we then assign to households in the JHPS/KHPS dataset.

In the food category, the CPI dataset has separate price indices for food-at-home and eatingout. We construct household-level price indices for food using a Stone price index, by taking a weighted average of the log of the price of eating-out and the log price of food-at-home, where the weights are the household's food budget shares of eating-out and of food-at-home. By employing each household's own within food relative consumption weights, this construction more accurately reflects the price for food faced by individual households than the total food index provided by the CPI.

\subsection{APPENDIX C: External Validation of Model Predictions}

The estimated resource shares are unobserved, and may suffer from measurement error or estimation error due to possible model misspecification (see, e.g. Calvi et al. 2019). To verify our results, we compare our estimated resource shares to individual private consumption given by the Japanese Panel Survey of Consumers (JPSC).

A unique feature of JPSC is that it asks the individual expenses and savings of each household member. Specifically, JPSC asks the following question (answered for both the wife and husband): How much expenditure, savings (including life insurance premiums etc.), and loan repayments did you pay this September? The answers are divided into : i) expenses/savings for all of my family ii)

JHPS/KHPS definition of Chubu region (Yamanashi, Nagano, Niigata, Fukui, Toyama, Ishikawa, Shizuoka, Gifu, and Aichi prefectures), we also merge Hokuriku and Tokai prefectures. With this merge, most prefectures belong to the same region between the JHPS/KHPS and CPI datasets with the following exceptions: Yamanashi and Nagano prefectures belong to Kanto [Chubu] region in CPI [JHPS/KHPS] dataset, and Mie prefecture belongs to Chubu [Kinki] region in CPI [JHPS/KHPS] dataset. About 3.7 percent of the Japanese population live in these three prefectures, according to the 2015 population census. See also, http://www.stat.go.jp/english/data/ kokusei/2015/final_en/final_en.html. This procedure follows Fujii and Lin (2018).

${ }^{2}$ There are 20 designated cities in Japan as of January 1, 2019. 
expenses/savings for me iii) expenses/savings for my husband iv) expenses/savings for my children v) expenses/savings for the others.

Categories ii), iii), and iv) are measures of private consumption for wives, husbands, and children. Category i) represents expenditures on goods that can be jointly consumed (like heat or gasoline). Previous studies have used inequality in private consumption to infer intra-household inequality in resource allocation. ${ }^{3}$ However, these types of estimates, at best based on data like the JPSC, are incomplete, in the sense that they do not account for the potentially large role that shared goods may have in the actual resources consumed by each family member. In the JPSC data, over two thirds of expenditures are listed as shared goods. ${ }^{4}$

Comparing our results to the JPSC data, first consider children's shares. Our model predicts children's resource shares in the range of 0.45 to 0.56 . This is consistent with the JPSC data, being above what JPSC reports for private children's consumption, and below the sum of JPSC's private children plus shared household expenditures. Second, our model estimates are that wives and husbands have roughly equal resource shares when there are no children present in the household. But the resource share of husbands increases up to around 1.6 times that of wives as the number of children in the household increases. This number is close to the ratio of private expenditures between husbands and wives, 1.5 - 2.3, found in the JPSC data. Taken together, these results provide evidence that our estimates are at least in ranges consistent with existing direct (albeit incomplete) measures of resource shares.

Finally we compare implications that one might draw about intra-household inequality from the JPSC data to estimates based on our model that accounts for and allocates expenditures on shared goods. Our estimates are that increasing the number of children decreases the wive's share by 35 percent while the husband's share decreases by only 10 percent. In the JPSC data, these numbers are 47 percent and 15 percent (based on summary statistics reported in Table 1 of Fujii

\footnotetext{
${ }^{3}$ Lise and Yamada (2014) look at JPSC households and find that there is a substantial difference between private consumption devoted to the wife, 6.3 percent, versus the husband, 15 percent. On average, 21.3 percent of the household expenditures are reported as the private consumption of either the wife or the husband, leaving 78.7 percent of household expenditures as public (expenditures for the family, children, and others). Fujii and Lin (2018) look at JPSC couples without children and also find similar patterns. The average private consumption devoted to the wife is 10 percent, versus the husband, 15 percent. 68 percent of household expenditures are devoted to the family. The remaining 4 percent of household expenditures are devoted to others. The previous findings imply that if we only consider private expenditures, the husband's resources are about 1.5-2.3 times of the wife's. The public expenditures, including both children and family expenditures, are around 70-80 percent of total household expenditures.

${ }^{4}$ Note, however, that expenditures for the family in the JPSC data include some durables that our data excludes, like furniture and electronics spending.
} 
and Ishikawa 2013). By failing to allocate shared goods, the JPSC appears to underestimate the relative contribution of wives vs. husbands to children's resources.

\subsection{Appendix D: Additional Tables and Figures}


Table 1: Elasticities Estimates of Single Men and Women

\begin{tabular}{lcc}
\hline \multicolumn{3}{c}{ Budget Elasticities } \\
\hline & Single women & Single men \\
Food & 0.74 & 0.81 \\
Clothing & 1.45 & 1.20 \\
Communication & 0.78 & 0.76 \\
Entertainment & 1.45 & 1.53 \\
Transportation & 1.13 & 1.24 \\
Utility & 0.54 & 0.43 \\
\hline
\end{tabular}

\begin{tabular}{|c|c|c|c|c|c|c|}
\hline \multicolumn{7}{|c|}{ Uncompensated Price Elasticities (single women) } \\
\hline & Food & Clothing & Communication & Entertainment & Transportation & Utility \\
\hline Food & -1.01 & 0.21 & -0.59 & 0.95 & -0.04 & -0.23 \\
\hline Clothing & 0.71 & -1.69 & 0.91 & -6.26 & 4.36 & 0.83 \\
\hline Communication & -2.57 & 0.97 & -0.37 & 1.61 & 0.56 & -1.05 \\
\hline Entertainment & 2.77 & -4.01 & 0.98 & -3.07 & -0.27 & 3.45 \\
\hline Transportation & -0.30 & 5.48 & 0.77 & -0.53 & -5.67 & 4.08 \\
\hline Utility & -1.37 & 1.03 & -0.92 & 4.51 & 2.25 & -5.14 \\
\hline \multicolumn{7}{|c|}{ Compensated Price Elasticities/Slutsky Matrix (single women) } \\
\hline & Food & Clothing & Communication & Entertainment & Transportation & Utility \\
\hline Food & -0.72 & 0.29 & -0.51 & 1.08 & 0.03 & -0.13 \\
\hline Clothing & 1.35 & -1.44 & 1.11 & -5.92 & 4.56 & 1.06 \\
\hline Communication & -2.33 & 1.05 & -0.26 & 1.74 & 0.64 & -0.96 \\
\hline Entertainment & 3.50 & -3.78 & 1.21 & -2.69 & -0.06 & 3.72 \\
\hline Transportation & 0.18 & 5.63 & 0.91 & -0.28 & -5.48 & 4.25 \\
\hline Utility & -1.25 & 1.07 & -0.89 & 4.58 & 2.29 & -5.05 \\
\hline \multicolumn{7}{|c|}{ Uncompensated Price Elasticities (single men) } \\
\hline & Food & Clothing & Communication & Entertainment & Transportation & Utility \\
\hline Food & -1.29 & -0.31 & -0.42 & 1.60 & 0.18 & -0.53 \\
\hline Clothing & -2.44 & -0.42 & -0.10 & 1.21 & -0.21 & 0.13 \\
\hline Communication & -1.85 & -0.25 & -1.67 & 2.89 & -0.02 & 0.46 \\
\hline Entertainment & 3.69 & -1.92 & 1.56 & -4.30 & -0.04 & 1.18 \\
\hline Transportation & 0.99 & 5.38 & -0.05 & -0.21 & -3.82 & -1.27 \\
\hline Utility & -2.11 & 0.60 & 0.16 & -1.27 & 2.67 & -0.45 \\
\hline \multicolumn{7}{|c|}{ Compensated Price Elasticities/Slutsky Matrix (single men) } \\
\hline & Food & Clothing & Communication & Entertainment & Transportation & Utility \\
\hline Food & -0.93 & -0.25 & -0.34 & 1.76 & 0.26 & -0.44 \\
\hline Clothing & -1.87 & -0.28 & 0.05 & 1.51 & -0.07 & 0.29 \\
\hline Communication & -1.59 & -0.19 & -1.57 & 3.03 & 0.05 & 0.53 \\
\hline Entertainment & 4.50 & -1.76 & 1.78 & -3.89 & 0.15 & 1.41 \\
\hline Transportation & 1.60 & 5.49 & 0.11 & 0.11 & -3.63 & -1.10 \\
\hline Utility & -2.01 & 0.62 & 0.18 & -1.22 & 2.69 & -0.39 \\
\hline
\end{tabular}


Table 2: Estimation Results: the Sharing Rule Parameters and Barten Scales (with Income Divided into Ten Brackets)

\begin{tabular}{|c|c|c|c|c|}
\hline \multirow[b]{2}{*}{ Panel A: the Sharing Rule } & \multicolumn{2}{|c|}{ Wife } & \multicolumn{2}{|c|}{ Husband } \\
\hline & Coef & Std Error & Coef & Std Error \\
\hline Constant & $-0.866^{* * *}$ & 0.370 & $-0.979^{* *}$ & 0.583 \\
\hline Difference in log income (female - male) & -0.159 & 0.140 & -0.118 & 0.171 \\
\hline Difference in age (female - male) & -0.003 & 0.012 & $0.012^{*}$ & 0.018 \\
\hline Number of children & $-0.362^{* * *}$ & 0.092 & -0.074 & 0.274 \\
\hline Minimum child age less 5 & -0.296 & 0.466 & -0.555 & 0.724 \\
\hline Female age less 39 & 0.235 & 0.245 & $0.735^{*}$ & 0.515 \\
\hline Wife some college & $0.985^{* * *}$ & 0.590 & -0.967 & 1.730 \\
\hline Husband some college & 0.446 & 0.480 & 0.292 & 0.564 \\
\hline Panel B: Estimates of Barten Scales & \multicolumn{2}{|c|}{ Barten scale } & \multicolumn{2}{|c|}{ Std Error } \\
\hline Food & \multicolumn{2}{|c|}{$0.808^{* * *}$} & \multicolumn{2}{|c|}{0.235} \\
\hline Clothing and shoes & \multicolumn{2}{|c|}{1.000} & \multicolumn{2}{|c|}{-} \\
\hline Communication & \multicolumn{2}{|c|}{$0.783^{* * *}$} & \multicolumn{2}{|c|}{0.310} \\
\hline Entertainment & \multicolumn{2}{|c|}{$0.626^{* *}$} & \multicolumn{2}{|c|}{0.303} \\
\hline Transportation & \multicolumn{2}{|c|}{$0.732^{* *}$} & \multicolumn{2}{|c|}{0.323} \\
\hline Utility & \multicolumn{2}{|c|}{0.510} & \multicolumn{2}{|c|}{0.428} \\
\hline
\end{tabular}

Notes: Income here is divided into ten brackets and becomes a discrete variable. Barten Scales are assumed to be homogeneous across all households. The Barten scales of clothing and shoes are assumed to be 1 (purely private). ${ }^{*}$ $\mathrm{p}<0.10,{ }^{* *} \mathrm{p}<0.05,{ }^{* * *} \mathrm{p}<0.01$. 
Figure 1: QUAIDS Fits for Singles and Couples with 0-4 Children
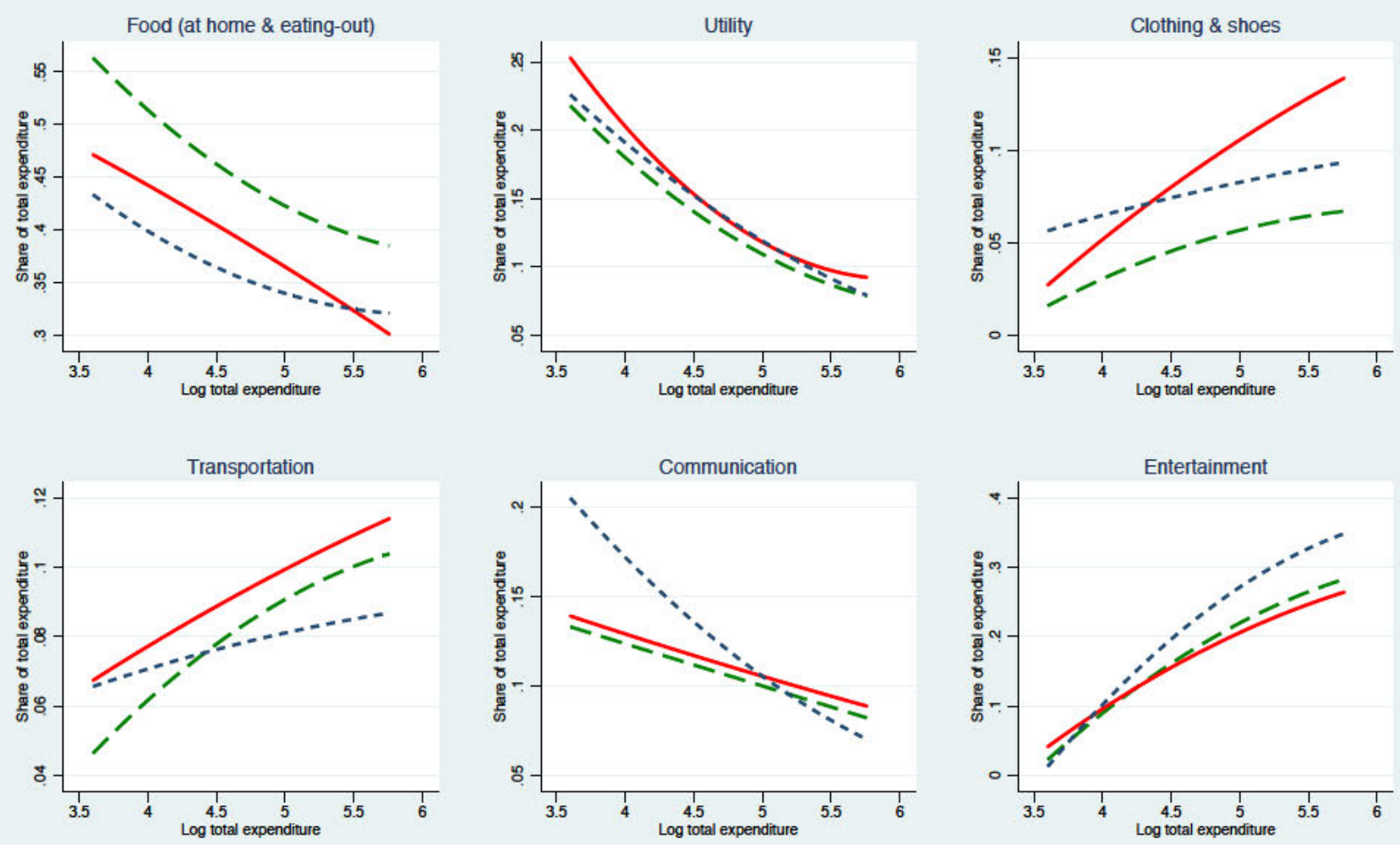